Boletín de la Sociedad Geológica Mexicana

VOLUMEN 67, NÚM. 1, 2015, P. 21-43

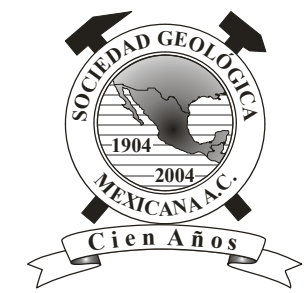

\title{
Cambios morfológicos y sedimentológicos en playas del sur del Golfo de México y del Caribe noroeste
}

\author{
Arturo Carranza-Edwards ${ }^{1, *}$, Antonio Zoilo Márquez-García ${ }^{2}$, Citlalli Itzel Tapia-Gonzalez ${ }^{3}$, \\ Leticia Rosales-Hoz ${ }^{1}$, Miguel Ángel Alatorre-Mendieta ${ }^{1}$ \\ ${ }^{1}$ Universidad Nacional Autónoma de México, Instituto de Ciencias del Mar y Limnología, Unidad Académica de Procesos Oceánicos \\ y Costeros, Ciudad Universitaria, Del. Coyoacán, México D.F., 04510, México. \\ ${ }^{2}$ Universidad Autónoma Metropolitana-Iztapalapa, Departamento de Hidrobiología, San Rafael Atlixco No. 186, Col. Vicentina, Del. \\ Iztapalapa, México D. F., 09400, México. \\ ${ }^{3}$ Posgrado de Maestría en Geomática, CENTROGEO, Contoy 137, esquina Chemax, Col. Lomas de Padierna, Del. Tlalpan, C.P. \\ 14240, México. \\ *dr.arturo.carranza@gmail.com
}

\begin{abstract}
Resumen
El presente trabajo tiene como objetivo comparar variaciones morfológicas y sedimentológicas entre las playas del Sur del Golfo de México y de la Riviera Maya (Caribe noroeste) realizando dos muestreos regionales de sedimentos del frente de playa, perfiles topográficos de las playas y analizando el posible efecto del ascenso del nivel del mar por el calentamiento global. La diferencia entre muestreos varía entre 26 años y 32 años. Se estudian perfiles de playa, variaciones de línea de costa, parámetros texturales y composición de arenas superficiales del frente de playa. En este estudio se considera el estado de marea, precipitaciones y eventos meteorológicos. Se encontraron en localidades geográficas cercanas, 23 estaciones en los muestreos antiguos y recientes. Los perfiles de playa presentan variaciones, siendo más largos en ocasiones para los muestreos recientes que para los antiguos. La concavidad de los perfiles de playa sugiere que hay más perfiles recientes característicos de erosión. Las líneas de playa analizadas mediante imágenes LANDSAT de diversos años, sugieren la influencia de procesos antrópicos y meteorológicos; estos últimos podrían indicar una conexión entre deposición y erosión de playas en localidades no muy alejadas. Tanto la comparación de parámetros texturales como composicionales demostraron su utilidad en el análisis comparativo de arenas de playa antiguas y recientes. Resultó más común encontrar clasificaciones más pobres en sedimentos recientes que en sedimentos antiguos, lo que puede sugerir una interferencia mayor de factores antrópicos en sedimentos recientes, o una mayor variación de los parámetros oceanográficos. A través del análisis de componentes principales se observa que el mayor peso estadístico para terrígenos está dado por minerales pesados y para sedimentos carbonatados por pellets, esta relación refleja condiciones favorables para la erosión y posible empobrecimiento de organismos litorales y de aves.
\end{abstract}

Palabras clave: Golfo de México, Riviera Maya, frente de playa, textura, composición de arenas, línea de costa.

\begin{abstract}
This study aims to compare morphological and sedimentological variations between the beaches of the Southern Gulf of Mexico and the Riviera Maya (Northwest Caribbean) by conducting two regional samplings of foreshore sediments, measuring topographic profiles of the beaches, and analyzing the potential impact of sea level rise from global warming. The time lapse between samplings was 26 and 32 years. Beach profiles, shoreline changes, textural parameters and composition of surficial beach sands from the foreshore were compared. This study considers the state of tide, rainfall and meteorological events. A total of 23 beach locations were studied: 19 for the Southern Gulf of Mexico and 4 for the Riviera Maya. The beach profiles show variations, with recent beaches sometimes being wider than the ancient ones. The concavity of the recent exposed beach profiles suggests that many of them are eroding. The
\end{abstract}


coastline contours were analyzed through LANDSAT images from several years. Variations of coastlines in different years suggest the influence of anthropogenic and meteorological processes, indicating a connection between deposition and erosion of beaches at locations that are not very far from each other. The comparisons of textural and compositional parameters proved to be useful in the comparative analysis of ancient and recent beach sands. It is noted that it is more common for recent sediments to be more poorly sorted compared to ancient sediments, which may suggest greater interference of anthropogenic factors in recent sediments or a greater variation in oceanographic parameters. The greater statistical weight is observed through principal component analysis and is given by heavy minerals in terrigenous sands, and in carbonate sediments by pellets; this relation reflects favorable conditions for erosion and a probable depletion of marine littoral organisms and birds.

Keywords: Gulf of Mexico, Riviera Maya, foreshore, beach face, sediment texture, sand composition, coastlines.

\section{Introducción}

Debido al aumento de las emisiones de gases de efecto invernadero (Feagin et al., 2005; Arkema et al., 2013) se produce un calentamiento global in crescendo, uno de sus efectos podría ser el incremento del nivel del mar, lo cual constituye una amenaza para muchos sitios del planeta pues se considera que dicha elevación amenaza con erosionar principalmente a las zonas costeras de pendiente suave, en tanto que las llanuras costeras asociadas con relieves más pronunciados resultan menos vulnerables al ascenso del nivel del mar. Sin embargo, según el quinto informe del Intergovernmental Panel of Climate Change (Church et al., 2013), el cambio promedio del nivel medio del mar en los últimos 30 años es del orden de $5 \mathrm{~cm}$ por lo que el efecto de este fenómeno en las zonas de estudio es inferior al $10 \%$ y no explicaría retrocesos en la línea de costa.

En México las costas del océano Atlántico presentan un mayor riesgo a la erosión por ascenso del nivel del mar que las del océano Pacífico, por tener éstas últimas un relieve más suave (Duncan et al., 2008). Para el caso de la zona costera del Golfo de México, cuya pendiente es suave $(5 / 1000)$ exceptuando los litorales relacionados con montañas volcánicas (Punta Delgada y Los Tuxtlas en el estado de Veracruz), se espera una mayor vulnerabilidad por el aumento del mar por transgresiones marinas de origen antrópico. Los problemas erosivos de playas y dunas se pueden amplificar por otras actividades antropogénicas, entre las cuales se pueden citar: 1) la construcción de represas en ríos, 2) instalación de ductos sumergidos, escolleras, rompeolas, etc., que son barreras del transporte litoral de sedimentos, 3) la extracción de agua por bombeo, de sal desde domos salinos, hidrocarburos y aguas subterráneas, que producen subsidencia del piso costero o marino (Fanos, 1995; Yuill et al., 2009; Carranza-Edwards, 2010).

En algunos sectores de la costa de México se ha visto la erosión de la línea costera (Tanner y Stapor Jr., 1971), donde la llanura de cordones litorales no había crecido en cerca de 50 años. Ortíz (1992) ha reportado importantes tasas de erosión para playas del estado de Tabasco y Hernández Santana et al. (2008) analizaron para Tabasco tasas anuales medias de erosión de 3 a $5 \mathrm{~m}$ de Sánchez Magallanes y de 8 a $9 \mathrm{~m}$ en la desembocadura del río San Pedro y San Pablo. De acuerdo con Peizhen et al. (2001) el calentamiento global no sólo ha causado erosión costera sino que además puede incrementar las tasas de sedimentación en la zona marina y acumulación en alguna otra parte del litoral, debido a que cuando se produce erosión en algunas localidades, en otras, se producirá sedimentación (Carranza-Edwards, 2010).

Carranza-Edwards et al. (1996) estudiaron las concentraciones de carbonatos en muestras del frente de playa beach face, (Carranza-Edwards y Caso-Chávez, 1994), encontrando que los valores más bajos de carbonatos en arenas de playas del Golfo de México son los del estado de Tabasco que son ricos en sedimentos terrígenos (siliciclásticos) derivado de los escurrimientos de las cuencas que incluyen tierras altas de Chiapas y Guatemala; estas playas se encuentran adyacentes a la región más rica en carbonatos, la cual se asocia con sedimentos carbonatados de la Península de Yucatán donde los terrígenos están prácticamente ausentes debido al suave relieve de la zona costera, lo que favorece el enriquecimiento de carbonatos en las playas. Desde el punto de vista granulométrico Carranza-Edwards (2001) estudia texturalmente 1100 muestras de playas de México, encontrando que el frente de playa es la zona con mínimos procesos de mezclas, siendo relativamente más estable, por tener esta sub zona niveles de energía menos agresivos dado el oleaje de flujo y reflujo de baja energía que se tiene en esta parte asociado con el frente de playa.

Este trabajo tiene como objetivo realizar un análisis comparativo de las características de 23 playas antiguas, 23 playas recientes y sus perfiles topográficos perpendiculares a la línea de costa, para ello se estudiaron los parámetros texturales, composicionales y petrológicos de arenas superficiales del frente de playa, tomando en cuenta las mareas, la precipitación y eventos meteorológicos, con el fin de entender los posibles cambios que han sufrido las playas a través de muestreos superficiales regionales con diferencias temporales de cerca de tres décadas en zonas de crecimiento demográfico importante como son Tabasco, Campeche y el norte de Quintana Roo, que se caracterizan por ser estados petroleros los dos primeros y turísticos los 
dos últimos.

\section{2. Área de estudio}

En la Figura 1 aparecen las estaciones de muestreo representadas con una línea, la cual corresponde con el muestreo antiguo y reciente.

Las cuatro principales provincias geológicas para el área de estudio propuestas por Ortega-Gutiérrez et al. (1992) son: 1) La cuenca deltaica de Tabasco constituida por sedimentos continentales del Cenozoico, 2) la Plataforma de Yucatán con sedimentos marino cenozoicos, 3) el cinturón Chiapaneco de pliegues y fallas, con rocas sedimentarias marinas cenozoicas, y 4) el Batolito de Chiapas que es plutónico del Paleozoico (Figura 2). Estas provincias son importantes por su extensión y por ser las principales fuentes de sedimentos hacia las partes bajas.

Considerando la construcción de los diversos represamientos (la Presa la Angostura se construyó desde 1964) es posible que los depósitos sedimentarios continentales de la cuenca deltaica de Tabasco contribuyan con una menor influencia en los aportes actuales hacia el mar. Al oeste de estas cuatro grandes provincias se encuentran la cuenca deltaica de Veracruz y el Macizo volcánico de Los Tuxtlas. Sus aportes hacia el litoral de los estados de Tabasco y Campeche tal vez sea de menor magnitud, ya que las corrientes litorales dominantes en el Sur del Golfo de México son de oeste a este según MarínGuzmán y Carranza-Edwards (2011); incluso estimaciones de campo para el muestreo antiguo así lo confirman en la mayoría de los casos.

Cabe señalar que los litorales de las costas de Tabasco, Campeche y Quintana Roo reciben con frecuencia el paso de huracanes (Figura 3).

$\mathrm{Al}$ oeste del sur del Golfo de México se encontraron durante los muestreos sedimentos terrígenos en Tabasco $\mathrm{y}$ en una playa de Campeche, mientras que en el resto de playas de Campeche y en la Riviera Maya las playas son de arenas carbonatadas. Las terrígenas se asocian con una zona montañosa de gran relieve y con rocas sedimentarias, volcánicas, plutónicas y metamórficas, mientras que las playas de sedimentos carbonatados pertenecientes a la Plataforma de Yucatán se asocian con un relieve suave en el Sur del Golfo de México y en la Riviera Maya.

En las figuras 4 a 6, la escala permite ubicar en detalle la posición de los muestreos espacio temporales regionales correspondientes. Al respecto se eligió que los puntos recientes se localizaran lo más cercano posible a los puntos antiguos. Temporalmente también se observan algunas variaciones por lo cual en la Tabla 1 se dan las coordenadas y las fechas del muestreo y del levantamiento de perfiles, con la finalidad de conocer las condiciones de precipitación en el momento del muestreo.

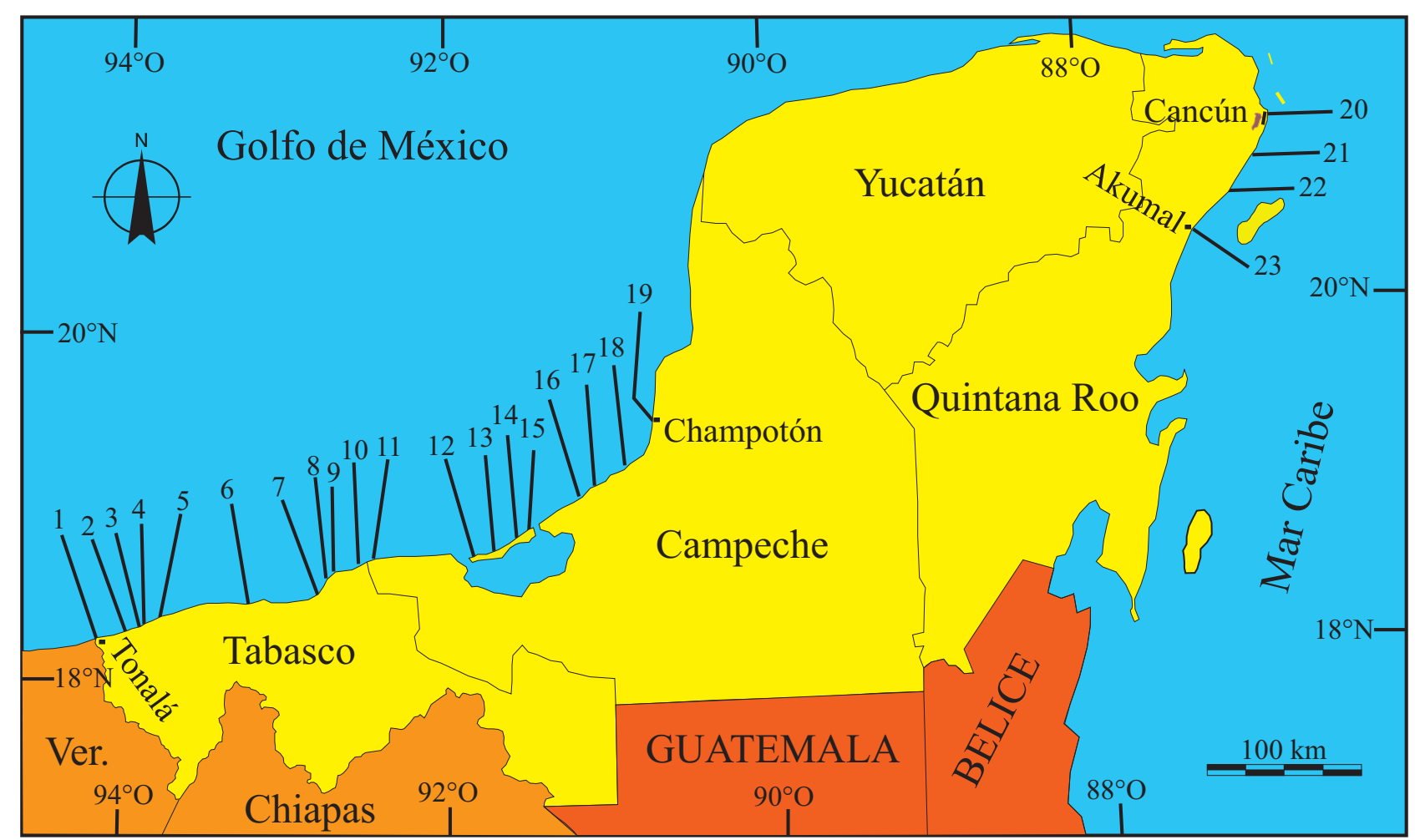

Figura 1. Área de estudio con estaciones de muestreo. Las estaciones 1 a 11 corresponden con terrígenos y las 12 a 23 con carbonatos. El sur del Golfo de México está representado por las estaciones 1 a 19 y el Caribe Norte (Riviera Maya) por las estaciones 20 a 23. 


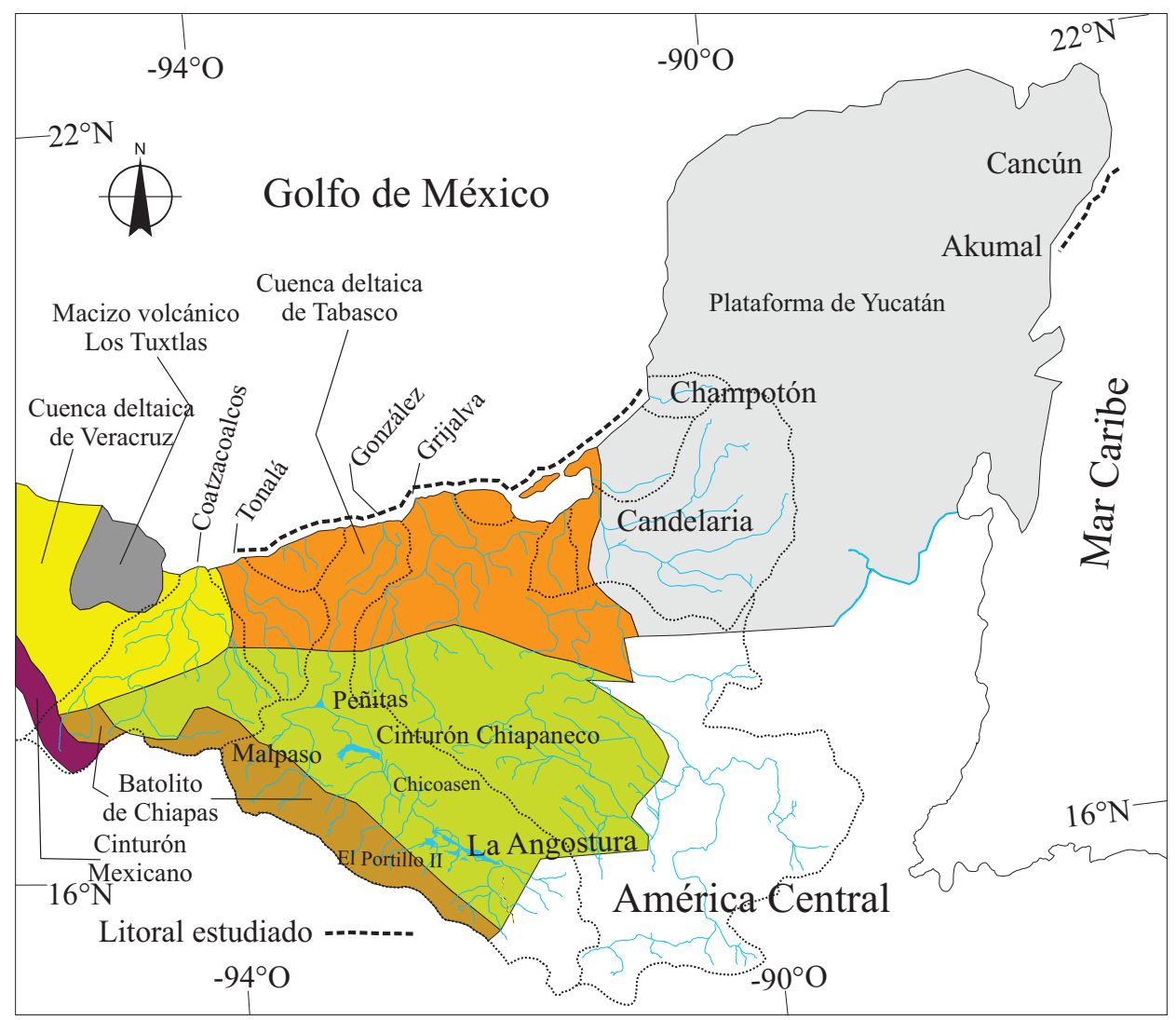

Figura 2. Provincias geológicas (modificado de Ortega-Gutiérrez, 1992) y principales cuencas de drenaje. Se aprecia la presa La Angostura, la cual es un lago artificial desde 1964. Los parte-aguas de las cuencas en líneas punteadas

\section{Fenómenos naturales que afectan a las líneas de costa}

El número de huracanes en las zonas de estudio se muestra en la Figura 3, en el período comprendido desde el año 1851 hasta el 2013 (NOAA, 2014). Se aprecia claramente la alta incidencia de huracanes en el Caribe en comparación con el Sur del Golfo de México (Figura 3). De acuerdo con King (1972) la marea influye de varias maneras en la playa: 1) generando morfologías específicas, 2) al variar la altura de la onda de marea se desplaza la posición de los rompeolas que es donde hay mayor disipación de energía, 3) la velocidad de la ola varía con la profundidad y esta depende de la marea por lo que el arrastre es distinto a lo largo del perfil de playa. Por esto, la distribución de los sedimentos no necesariamente es uniforme a lo largo del perfil de la playa y conviene tener una referencia de la ubicación de la muestra, con los datos de marea referidos al nivel medio del mar.

En cuanto a la precipitación en tierra, es importante considerarla porque los ríos transportan sedimentos hacía las playas y en época de tormentas y huracanes, la carga de sedimentos fluviales es aún mayor que en condiciones normales. a)

b)
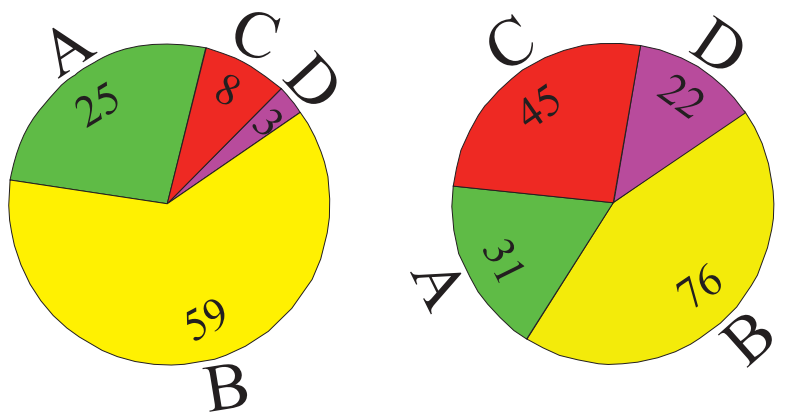

Figura 3. Huracanes ocurridos en el período 1851-2013 en las zonas de estudio de acuerdo con la escala cromática de la NOAA (2014), según la cual $\mathrm{A}=$ Depresión Tropical, $\mathrm{B}=$ Tormenta Tropical, $\mathrm{C}=$ Huracán, $\mathrm{D}=$ Huracán Intenso; a) 95 eventos ocurridos con trayectorias pasando por Tabasco y Campeche, y b) 174 eventos afectando al Caribe mexicano

Se utilizaron los datos de campo de localización, fecha y hora para definir la altura de la marea para las diversas estaciones en el momento del levantamiento de los perfiles (Figuras 4, 5 y 6) con base en las Tablas de Marea del Instituto de Geofísica (1991) y los datos de precipitación mensual (Tabla 2) obtenidos del software Eric III (Versión V.1.1) del IMTA actualizado al 2006. La información para 
Tabla 1. Coordenadas de playas antiguas (A) y recientes (R) y fechas de muestreo.

\begin{tabular}{|c|c|c|c|c|c|c|c|c|c|c|c|c|c|c|}
\hline Playas & $\mathrm{A}$ & WL & $\mathrm{NL}$ & Año & Mes & Día & Hora & $\mathrm{R}$ & WL & NL & Año & Mes & Día & $\mathrm{Hr}$ \\
\hline Tonalá & 1 & -94.126 & 18.215 & 1981 & $\mathrm{~V}$ & 28 & 15.3 & 1 & -94.128 & 18.213 & 2011 & IX & 8 & $\overline{18.0}$ \\
\hline Pailebot & 2 & -93.935 & 18.275 & 1981 & V & 28 & 18.0 & 2 & -93.942 & 18.272 & 2011 & IX & 8 & 16.0 \\
\hline Santa Ana & 3 & -93.861 & 18.298 & 1981 & V & 29 & 17.8 & 3 & -93.852 & 18.300 & 2011 & IX & 8 & 14.0 \\
\hline Macayo & 4 & -93.829 & 18.309 & 1981 & V & 29 & 15.3 & 4 & -93.845 & 18.305 & 2011 & IX & 7 & 17.0 \\
\hline El Pajonal & 5 & -93.753 & 18.335 & 1981 & V & 29 & 13.1 & 5 & -93.722 & 18.346 & 2011 & IX & 7 & 15.0 \\
\hline El Limón & 6 & -93.214 & 18.440 & 1981 & V & 25 & 17.3 & 6 & -93.159 & 18.441 & 2011 & IX & 4 & 11.0 \\
\hline Miramar & 7 & -92.788 & 18.491 & 1981 & V & 27 & 18.5 & 7 & -92.755 & 18.520 & 2011 & IX & 3 & 17.0 \\
\hline Carrillo Puerto & 8 & -92.730 & 18.545 & 1981 & V & 27 & 14.0 & 8 & -92.714 & 18.576 & 2011 & IX & 3 & 12.0 \\
\hline El Bosque & 9 & -92.678 & 18.612 & 1981 & V & 26 & 18.5 & 9 & -92.692 & 18.614 & 2011 & IX & 3 & 10.0 \\
\hline Boquerón & 10 & -92.512 & 18.639 & 1981 & V & 26 & 13.8 & 10 & -92.513 & 18.638 & 2011 & IX & 2 & 16.0 \\
\hline Campechito & 11 & -92.428 & 18.660 & 1981 & V & 24 & 17.3 & 11 & -92.467 & 18.650 & 2007 & V & 1 & 8.0 \\
\hline Playa Norte & 12 & -91.810 & 18.665 & 1981 & V & 23 & 17.1 & 12 & -91.841 & 18.664 & 2007 & V & 2 & 18.0 \\
\hline Bahamita & 13 & -91.701 & 18.698 & 1981 & V & 23 & 15.4 & 13 & -91.712 & 18.692 & 2007 & V & 2 & 15.0 \\
\hline Paso Real & 14 & -91.556 & 18.767 & 1981 & V & 23 & 12.8 & 14 & -91.564 & 18.763 & 2007 & V & 2 & 13.0 \\
\hline Isla Aguada & 15 & -91.459 & 18.824 & 1981 & V & 22 & 17.1 & 15 & -91.499 & 18.788 & 2007 & V & 2 & 12.0 \\
\hline Sabancuy & 16 & -91.279 & 18.952 & 1981 & V & 22 & 14.3 & 16 & -91.189 & 18.992 & 2007 & V & 3 & 10.0 \\
\hline Canchec & 17 & -91.118 & 19.033 & 1981 & V & 21 & 17.1 & 17 & -91.089 & 19.057 & 2013 & IX & 27 & 9.0 \\
\hline Xochen & 18 & -90.903 & 19.181 & 1981 & V & 21 & 15.4 & 18 & -90.897 & 19.188 & 2013 & IX & 27 & 9.5 \\
\hline Champotón & 19 & -90.722 & 19.363 & 1981 & V & 21 & 12.1 & 19 & -90.722 & 19.366 & 2007 & V & 3 & 10.0 \\
\hline Cancún & 20 & -86.749 & 21.128 & 1982 & XI & 9 & 16.1 & 20 & -86.768 & 21.090 & 2013 & II & 5 & 11.0 \\
\hline Puerto Morelos & 21 & -86.882 & 20.840 & 1982 & XI & 9 & 13.0 & 21 & -86.877 & 20.845 & 2013 & II & 6 & 11.0 \\
\hline Playa del Carmen & 22 & -87.067 & 20.626 & 1982 & XI & 9 & 10.7 & 22 & -87.069 & 20.627 & 2005 & VIII & 10 & 12.0 \\
\hline Akumal & 23 & -87.315 & 20.394 & 1982 & $\mathrm{XI}$ & 8 & 18.1 & 23 & -87.316 & 20.394 & 2005 & VIII & 11 & 12.0 \\
\hline
\end{tabular}

Tabla 2. Marea y lluvia mensual ( $\mathrm{mm}$ ) en playas antiguas (A) y recientes (R).

\begin{tabular}{lcccccc}
\hline Playa & A & Marea & Lluvia en $\mathrm{mm}$ & $\mathrm{R}$ & Marea Lluvia $\mathrm{mm}$ \\
\hline Tonalá & 1 & $\mathrm{a}$ & 129 & 1 & $\mathrm{~d}$ & 242 \\
Pailebot & 2 & $\mathrm{a}$ & 129 & 2 & $\mathrm{~d}$ & 242 \\
Santa Ana & 3 & $\mathrm{c}$ & 129 & 3 & $\mathrm{~d}$ & 242 \\
Macayo & 4 & $\mathrm{a}$ & 129 & 4 & $\mathrm{v}$ & 242 \\
El Pajonal & 5 & $\mathrm{~d}$ & 129 & 5 & $\mathrm{v}$ & 242 \\
El Limón & 6 & $\mathrm{c}$ & 129 & 6 & $\mathrm{~d}$ & 242 \\
Miramar & 7 & $\mathrm{a}$ & 129 & 7 & $\mathrm{a}$ & 242 \\
Carrillo Puerto & 8 & $\mathrm{~d}$ & 129 & 8 & $\mathrm{v}$ & 242 \\
El Bosque & 9 & $\mathrm{a}$ & 129 & 9 & $\mathrm{~d}$ & 242 \\
Boquerón & 10 & $\mathrm{~d}$ & 129 & 10 & $\mathrm{a}$ & 242 \\
Campechito & 11 & $\mathrm{c}$ & 129 & 11 & $\mathrm{c}$ & 0 \\
Playa Norte & 12 & $\mathrm{c}$ & 129 & 12 & $\mathrm{v}$ & 0 \\
Bahamita & 13 & $\mathrm{c}$ & 129 & 13 & $\mathrm{~d}$ & 0 \\
Paso Real & 14 & $\mathrm{c}$ & 129 & 14 & $\mathrm{~d}$ & 0 \\
Isla Aguada & 15 & $\mathrm{c}$ & 129 & 15 & $\mathrm{c}$ & 0 \\
Sabancuy & 16 & $\mathrm{c}$ & 129 & 16 & $\mathrm{c}$ & 0 \\
Canchec & 17 & $\mathrm{c}$ & 129 & 17 & $\mathrm{~d}$ & 103 \\
Xochen & 18 & $\mathrm{a}$ & 129 & 18 & $\mathrm{~d}$ & 103 \\
Champotón & 19 & $\mathrm{a}$ & 129 & 19 & $\mathrm{c}$ & 0 \\
Cancún & 20 & $\mathrm{c}$ & 101 & 20 & $\mathrm{v}$ & 26 \\
Puerto Morelos & 21 & $\mathrm{a}$ & 101 & 21 & $\mathrm{v}$ & 26 \\
Playa del Carmen & 22 & $\mathrm{a}$ & 101 & 22 & $\mathrm{v}$ & 31 \\
Akumal & 23 & $\mathrm{~d}$ & 101 & 23 & $\mathrm{v}$ & 31 \\
\hline
\end{tabular}

$\mathrm{a}=$ ascenso, $\mathrm{c}=$ cresta, $\mathrm{d}=$ descenso, $\mathrm{v}=$ valle

Para fuentes referirse a Métodos y materiales estudiados.

los muestreos recientes se obtuvo de CONAGUA (2014).

De acuerdo con Fernández-Eguiarte et al. (1992a y 1992b) las masas de agua se mueven en el Caribe hacia el norte en forma dominante, pero las estimaciones de deriva con pelota de tenis, cuando se elaboraron los perfiles antiguos, fueron hacia el Sur para Cancún, Puerto Morelos y Akumal, mientras que para Playa del Carmen se obtuvo una corriente estacionaria. Merino-Ibarra (1986) usando tarjetas de deriva, encontró que además de la Corriente de Yucatán que va hacia el norte, se presentan contracorrientes hacia el sur sobre todo en las partes donde el litoral es menos rectilíneo.

Los restos de detritos biogénicos recientes pueden ser transportados por corrientes litorales y fragmentados por el efecto de las mismas, así como por el oleaje. En el caso de fósiles o líticos calcáreos de rocas sedimentarias del continente no se espera que lleguen a la playa a través de los ríos, pues antes sufrirían un fuerte intemperismo físico y químico. En cambio, los ríos son aportadores de enormes cantidades de carbonatos en solución hacía el mar lo que lleva materia prima abundante para que los organismos marinos construyan sus testas y esqueletos calcáreos. La provincia carbonatada también puede contribuir con restos de organismos calcáreos desplazados hacía el suroeste por la Corriente de Yucatán (Fernández-Eguiarte et al., 1992a y 1992b).

\section{Métodos y materiales estudiados}

Como parte de una investigación conjunta del Instituto de Ciencias del Mar y Limnología de la UNAM y del Departamento de Hidrobiología de la UAM-Iztapalapa, se utilizaron muestras de sedimentos superficiales del frente de playa tanto antiguas como recientes. Se recolectó el primer centímetro de sedimento litoral el cual representa 
las propiedades texturales y composicionales del sedimento en el momento del muestreo.

Se recolectaron arenas terrígenas en las estaciones 1 a 11 (10 del estado de Tabasco y una del estado de Campeche) y carbonatadas desde la estación 12 hasta la 23 (ocho del estado de Campeche y cuatro para la Riviera Maya). Se obtuvieron perfiles de playa (Figuras 4, 5 y 6), utilizando estadal, medidor óptico de distancias y nivel. Para los muestreos recientes los datos fueron obtenidos y descargados a partir de un GPS Geodésico marca Thales Modelo ProMark 3, con precisión de 5 a $12 \mathrm{~mm}$. Los perfiles se construyeron utilizando como software Corel Draw (versión 12), con escala vertical 1:250 y horizontal 1:500, para obtener una exageración vertical de $2 \mathrm{x}$.

Los carbonatos en las arenas de playa se determinaron utilizando la técnica propuesta por Hesse (1971), que consiste en la titulación con hidróxido de sodio $0.3 \mathrm{~N}$ del exceso de ácido clorhídrico $0.1 \mathrm{~N}$ agregado que no reacciona con los carbonatos presentes en la muestra del sedimento analizado (Tabla 3). La exactitud se evaluó usando carbonato de calcio. El porcentaje de recuperación fue de $98.90 \%$ y el coeficiente de variación fue de 0.84 . Los biógenos se determinaron mediante conteos de 300 granos en lámina delgada con el microscopio petrográfico Olympus BH-2 (Tabla 3).

El análisis granulométrico para arenas de 23 muestreos antiguos y de 23 muestreos recientes se hizo con tamices US Standard Soil cada $1 / 4$ de $\phi$. Con los porcentajes de pesos determinados para cada fracción se calcularon los parámetros texturales (Tabla 4) con las fórmulas sugeridas

Tabla 3. Carbonatos y biógenos (B) en arenas de playas antiguas (A) y recientes $(\mathrm{R})$.

\begin{tabular}{lcccccccc}
\hline Playa & Region & $\mathrm{S} / \mathrm{C}$ & $\mathrm{A}$ & $\mathrm{CO}_{3}(\%)$ & $\mathrm{B} \%$ & $\mathrm{R}$ & $\mathrm{CO}_{3}(\%)$ & $\mathrm{B} \%$ \\
\hline Tonalá & $\mathrm{SGM}$ & $\mathrm{S}$ & 1 & 3.21 & 0 & 1 & 1.34 & 0 \\
Pailebot & $\mathrm{SGM}$ & $\mathrm{S}$ & 2 & 3.21 & 1 & 2 & 13.46 & 3 \\
Santa Ana & $\mathrm{SGM}$ & $\mathrm{S}$ & 3 & 4.42 & 1 & 3 & 1.34 & 0 \\
Macayo & $\mathrm{SGM}$ & $\mathrm{S}$ & 4 & 3.85 & 1 & 4 & 2.18 & 3 \\
El Pajonal & $\mathrm{SGM}$ & $\mathrm{S}$ & 5 & 3.85 & 0 & 5 & 1.35 & 1 \\
El Limón & $\mathrm{SGM}$ & $\mathrm{S}$ & 6 & 3.21 & 1 & 6 & 4.67 & 2 \\
Miramar & $\mathrm{SGM}$ & $\mathrm{S}$ & 7 & 5.14 & 4 & 7 & 5.53 & 3 \\
Carrillo Puerto & $\mathrm{SGM}$ & $\mathrm{S}$ & 8 & 5.00 & 3 & 8 & 5.47 & 1 \\
El Bosque & $\mathrm{SGM}$ & $\mathrm{S}$ & 9 & 5.14 & 9 & 9 & 15.57 & 0 \\
Boquerón & $\mathrm{SGM}$ & $\mathrm{S}$ & 10 & 5.46 & 9 & 10 & 9.69 & 5 \\
Campechito & $\mathrm{SGM}$ & $\mathrm{S}$ & 11 & 2.57 & 22 & 11 & 5.55 & 5 \\
Playa Norte & $\mathrm{SGM}$ & $\mathrm{C}$ & 12 & 73.90 & 61 & 12 & 88.00 & 58 \\
Bahamita & $\mathrm{SGM}$ & $\mathrm{C}$ & 13 & 85.57 & 65 & 13 & 90.35 & 93 \\
Paso Real & $\mathrm{SGM}$ & $\mathrm{C}$ & 14 & 93.82 & 92 & 14 & 97.56 & 93 \\
Isla Aguada & $\mathrm{SGM}$ & $\mathrm{C}$ & 15 & 73.28 & 73 & 15 & 97.27 & 96 \\
Sabancuy & $\mathrm{SGM}$ & $\mathrm{C}$ & 16 & 87.40 & 96 & 16 & 96.05 & 100 \\
Canchec & $\mathrm{SGM}$ & $\mathrm{C}$ & 17 & 91.25 & 92 & 17 & 97.73 & 98 \\
Xochen & $\mathrm{SGM}$ & $\mathrm{C}$ & 18 & 87.40 & 99 & 18 & 91.62 & 98 \\
Champotón & $\mathrm{SGM}$ & $\mathrm{C}$ & 19 & 84.18 & 99 & 19 & 89.69 & 98 \\
Cancún & $\mathrm{RM}$ & $\mathrm{C}$ & 20 & 97.68 & 99 & 20 & 93.89 & 98 \\
Puerto Morelos & $\mathrm{RM}$ & $\mathrm{C}$ & 21 & 83.54 & 100 & 21 & 95.90 & 100 \\
Playa del Carmen & $\mathrm{RM}$ & $\mathrm{C}$ & 22 & 86.76 & 100 & 22 & 95.49 & 100 \\
Akumal & $\mathrm{RM}$ & $\mathrm{C}$ & 23 & 87.40 & 100 & 23 & 87.06 & 100 \\
\hline
\end{tabular}

$\mathrm{SGM}=$ Sur del Golfo de México, $\mathrm{RM}=$ Riviera Maya, $\mathrm{S}=$ siliciclastos, $\mathrm{C}=$ carbonatos. por Folk (1980), obteniendo el tamaño gráfico promedio $(\mathrm{Mz} \phi)$, la desviación gráfica inclusiva $(\sigma \mathrm{I} \phi)$, el grado de asimetría (SkI) y la curtosis (KG).

Se hicieron láminas delgadas de las muestras para el conteo tradicional de 300 granos utilizando el microscopio petrográfico Olympus modelo BH-2. El método utilizado para los conteos es el sugerido por Basu (1976), esto es, contando una partícula solo una vez sin importar el tamaño de la misma. Para arenas terrígenas de 11 playas (Tabla 5), se utilizaron las características ópticas de las partículas para hacer el análisis modal por: cuarzo monocristalino, plagioclasas, feldespatos potásicos, fragmentos de rocas: volcánicas (FRV), sedimentarias (FRS), plutónicas (FRP) y metamórficas (FRM) y minerales pesados (principalmente magnetita, ilmenita y piroxenas), determinados siguiendo el método de Potter (1978) y de Franzinelli y Potter (1983). Para sedimentos carbonatados se contaron los restos recientes de testas o esqueletos de moluscos, briozoarios, algas calcáreas, pellets, oolitos, corales y equinodermos, foraminíferos y beach rock o roca de playa (Tabla 6).

El análisis de componentes principales (Loska y Wiechula, 2003; Hair et al., 1998) es una técnica ampliamente utilizada en el área de Ciencias de la Tierra, que permite reducir un conjunto grande de datos en un número pequeño de variables o factores, cada uno de los cuales representa un grupo de variables que se interrelacionan dentro de la serie de datos. El Análisis Jerárquico de Clúster (Mico et al., 2006) es una técnica de clasificación de datos, donde los objetos de un mismo grupo son más similares entre sí que a los de otros grupos. La técnica empleada en el presente trabajo usó agrupamiento de vinculación simple, que considera la distancia mínima entre los parámetros en estudio. La clasificación de las muestras en grupos (clusters) se basa en una observación visual del dendograma. El software utilizado en el procesamiento de datos fue Statistica 6.0. El coeficiente de correlación de Pearson se usó para identificar la relación entre parámetros.

Los mapas de líneas de costa se generaron a partir de múltiples fuentes de información: se compilaron mapas topográficos (1:50000) del INEGI para los muestreos antiguos del sur del Golfo de México (1981) y del Caribe Norte (1982) con la finalidad de obtener la posición exacta de cada una de las estaciones de muestreo, las cartas fueron georreferenciadas y reproyectadas en ArcGIS 10.1. Para la extracción de líneas de costa se usaron imágenes LANDSAT y se llevó a cabo un procesamiento previo de imágenes LANDSAT en el software ENVI 4.7; siguiendo la metodología de Alesheikh et al. (2007) se realizó la extracción de las líneas de costa en ERDAS 2013 y para la edición cartográfica se utilizó ArcGIS 10.1. En la Tabla 7 se presentan las fechas de las imágenes utilizadas y los tipos de sensores que se usaron en cada caso. Se eligieron dos casos representativos por cada estado (Tabasco, Campeche, Quintana Roo). La resolución de las imágenes LANDSAT recientes es de $30 \mathrm{~m}$ por $30 \mathrm{~m}$, en tanto que en las antiguas es de $60 \mathrm{~m}$ por $60 \mathrm{~m}$, lo cual se aprecia en los contornos 
Tabla 4.- Parámetros texturales de arenas de playas antiguas (1) y recientes (2).

\begin{tabular}{|c|c|c|c|c|c|c|c|c|c|}
\hline No. & Playa & $\mathrm{Mz}^{(1)}$ & $\mathrm{Mz}^{(2)}$ & $\sigma \mathrm{I} \phi^{(1)}$ & $\sigma \mathrm{II} \phi^{(2)}$ & $\mathrm{Ski}^{(1)}$ & $\mathrm{Ski}^{(2)}$ & $\mathrm{K}_{\mathrm{G}}^{(1)}$ & $\mathrm{K}_{\mathrm{G}}^{(2)}$ \\
\hline \multicolumn{10}{|c|}{ Arenas terrígenas del Sur del Golfo de México. } \\
\hline 1 & Tonalá & 1.54 & 1.46 & 0.40 & 0.58 & -0.20 & 0.17 & 0.90 & 0.69 \\
\hline 2 & Pailebot & 2.12 & 1.46 & 0.49 & 0.62 & -0.26 & 0.23 & 0.77 & 0.63 \\
\hline 3 & Santa Ana & 2.03 & 1.79 & 0.52 & 0.82 & 0.06 & -0.07 & 0.74 & 0.81 \\
\hline 4 & Macayo & 1.73 & 1.90 & 0.26 & 1.13 & 0.01 & 0.86 & 1.03 & 0.79 \\
\hline 5 & El Pajonal & 1.72 & 1.88 & 0.37 & 0.43 & 0.09 & 0.00 & 1.05 & 1.13 \\
\hline 6 & El Limón & 2.02 & 1.54 & 0.36 & 0.62 & -0.09 & -0.23 & 1.01 & 0.81 \\
\hline 7 & Miramar & 2.39 & 2.46 & 0.33 & 0.42 & -0.04 & 0.14 & 1.03 & 0.80 \\
\hline 8 & Carrillo Puerto & 2.55 & 2.38 & 0.29 & 0.32 & -0.09 & 0.13 & 1.06 & 0.64 \\
\hline 9 & El Bosque & 2.53 & 2.46 & 0.32 & 0.42 & -0.13 & 0.34 & 1.07 & 0.80 \\
\hline 10 & Boquerón & 2.42 & 2.38 & 0.32 & 0.35 & -0.05 & 0.00 & 0.98 & 0.80 \\
\hline 11 & Campechito & 2.32 & 2.67 & 0.29 & 0.35 & -0.10 & -0.54 & 1.00 & 3.68 \\
\hline \multicolumn{10}{|c|}{ Arenas carbonatadas del Sur del Golfo de México } \\
\hline 12 & Playa Norte & 2.11 & 1.72 & 0.54 & 1.64 & -0.12 & -0.48 & 1.03 & 0.69 \\
\hline 13 & Bahamita & 1.67 & 0.84 & 0.70 & 1.04 & 0.46 & -0.10 & 1.05 & 1.04 \\
\hline 14 & Paso Real & -1.13 & 1.51 & 2.06 & 1.33 & -0.12 & -0.05 & 1.05 & 0.87 \\
\hline 15 & Isla Aguada & 1.94 & 0.70 & 0.48 & 0.70 & -0.42 & -0.29 & 0.88 & 1.27 \\
\hline 16 & Sabancuy & 1.54 & 0.74 & 0.80 & 0.87 & -0.05 & -0.03 & 0.86 & 1.24 \\
\hline 17 & Canchec & 0.97 & 1.49 & 1.03 & 1.35 & 0.14 & 0.00 & 0.90 & 0.81 \\
\hline 18 & Xochen & 1.64 & 2.08 & 0.65 & 0.60 & -0.03 & 0.01 & 0.96 & 1.63 \\
\hline 19 & Champotón & 0.57 & 0.26 & 1.60 & 0.92 & 0.08 & -0.63 & 0.90 & 0.70 \\
\hline \multicolumn{10}{|c|}{ Arenas carbonatadas de la Riviera Maya } \\
\hline 20 & Cancún & 2.05 & 1.13 & 0.35 & 0.53 & -0.19 & -0.09 & 1.07 & 0.93 \\
\hline 21 & Puerto Morelos & 2.36 & 2.04 & 0.40 & 0.65 & -0.19 & -0.15 & 1.07 & 0.93 \\
\hline 22 & Playa del Carmen & 1.95 & 0.48 & 0.51 & 0.48 & -0.13 & 0.08 & 0.92 & 1.02 \\
\hline 24 & Akumal & 1.02 & 1.50 & 0.88 & 0.92 & 0.72 & 0.69 & 2.44 & 0.68 \\
\hline
\end{tabular}

Tabla 5. Petrografía de arenas terrígenas antiguas (A) y recientes (R).

\begin{tabular}{ccccccccc}
\hline Estación & Qm & Fp & Fk & FRV & FRS & FRP & FRM & MP \\
\hline 1A & 26.0 & 20.7 & 6.3 & 5.0 & 20.0 & 3.0 & 18.0 & 1.0 \\
2A & 36.3 & 18.0 & 4.7 & 6.7 & 6.7 & 6.0 & 18.0 & 3.7 \\
3A & 34.0 & 10.3 & 3.0 & 3.6 & 21.3 & 5.7 & 19.3 & 2.7 \\
4A & 31.7 & 20.0 & 9.0 & 0.3 & 13.0 & 3.7 & 18.3 & 4.0 \\
5A & 24.0 & 9.0 & 2.0 & 0.3 & 11.7 & 3.3 & 13.7 & 36.0 \\
6A & 27.7 & 14.0 & 4.3 & 3.7 & 8.3 & 10.3 & 27.7 & 4.0 \\
7A & 19.3 & 17.0 & 6.0 & 16.0 & 15.0 & 7.0 & 16.0 & 3.7 \\
8A & 27.3 & 23.0 & 5.0 & 0.3 & 23.7 & 5.3 & 7.7 & 7.7 \\
9A & 25.7 & 29.3 & 3.0 & 0.3 & 17.7 & 5.7 & 10.3 & 8.0 \\
10A & 10.3 & 33.0 & 9.3 & 1.7 & 14.7 & 7.3 & 17.7 & 6.0 \\
11A & 28.3 & 3.7 & 3.0 & 2.0 & 18.7 & 7.0 & 24.3 & 13.0 \\
1R & 39.7 & 15.3 & 4.0 & 12.0 & 9.0 & 4.0 & 9.7 & 6.3 \\
2R & 22.7 & 7.3 & 11.0 & 10.3 & 2.0 & 17.3 & 28.7 & 0.7 \\
3R & 33.7 & 17.7 & 4.3 & 15.0 & 3.0 & 2.7 & 18.3 & 5.3 \\
4R & 41.7 & 16.0 & 2.0 & 17.7 & 1.7 & 2.0 & 13.7 & 5.3 \\
5R & 29.3 & 22.0 & 3.7 & 17.0 & 2.3 & 7.0 & 14.7 & 4.0 \\
6R & 19.3 & 5.7 & 1.0 & 1.7 & 9.7 & 0.7 & 5.3 & 56.7 \\
7R & 42.0 & 14.7 & 1.3 & 6.0 & 11.0 & 1.0 & 19.0 & 5.0 \\
8R & 38.0 & 10.3 & 1.7 & 15.0 & 8.0 & 1.7 & 21.0 & 4.3 \\
9R & 26.7 & 4.7 & 1.0 & 2.0 & 23.3 & 0.7 & 4.0 & 37.7 \\
10R & 34.3 & 9.7 & 1.0 & 7.7 & 14.0 & 5.0 & 25.7 & 2.7 \\
11R & 36.3 & 13.0 & 2.0 & 3.7 & 9.3 & 6.0 & 27.0 & 2.7 \\
\hline
\end{tabular}

$\mathrm{Qm}=$ cuarzo, $\mathrm{Fp}=$ plagioclasas, $\mathrm{Fk}=$ feldespatos potásicos, Fragmentos de rocas: volcánicas. (FRV), sedimentarias (FRS), plutónicas (FRP), metamórficas (FRM) y minerales pesados (MP).
Tabla 6. Petrografía de arenas carbonatadas en playas antiguas (A) y recientes $(\mathrm{R})$.

\begin{tabular}{ccccccccc}
\hline Estación & Molus & Brio & A C & Pellets & oolit & C\&E & Foras & $B R$ \\
\hline $12 \mathrm{~A}$ & 37.3 & 11.0 & 0.0 & 29.0 & 0.0 & 11.0 & 2.0 & 9.7 \\
$13 \mathrm{~A}$ & 45.7 & 13.3 & 7.0 & 28.0 & 0.0 & 3.0 & 1.0 & 2.0 \\
$14 \mathrm{~A}$ & 52.0 & 13.3 & 3.0 & 15.0 & 0.0 & 4.0 & 7.0 & 5.7 \\
$15 \mathrm{~A}$ & 29.0 & 7.7 & 5.7 & 36.0 & 0.0 & 11.3 & 3.0 & 7.3 \\
$16 \mathrm{~A}$ & 36.0 & 12.0 & 3.0 & 29.0 & 0.0 & 7.0 & 4.0 & 9.0 \\
$17 \mathrm{~A}$ & 35.0 & 10.0 & 3.0 & 35.7 & 0.0 & 4.0 & 4.3 & 8.0 \\
$18 \mathrm{~A}$ & 35.0 & 13.3 & 0.0 & 30.0 & 0.0 & 0.0 & 0.0 & 21.7 \\
$19 \mathrm{~A}$ & 35.7 & 14.0 & 2.0 & 39.0 & 0.0 & 2.3 & 0.0 & 7.0 \\
20A & 3.0 & 6.3 & 4.0 & 16.7 & 52.7 & 11.3 & 0.0 & 6.0 \\
21A & 0.0 & 5.7 & 5.0 & 48.3 & 10.0 & 20.0 & 2.0 & 9.0 \\
22A & 0.0 & 16.0 & 11.0 & 36.0 & 3.0 & 24.3 & 5.7 & 4.0 \\
23A & 6.0 & 7.0 & 15.0 & 13.0 & 0.0 & 38.0 & 4.0 & 17.0 \\
$12 \mathrm{R}$ & 78.3 & 6.3 & 2.3 & 9.0 & 0.0 & 0.0 & 3.3 & 0.7 \\
$13 \mathrm{R}$ & 80.0 & 2.0 & 2.0 & 13.0 & 0.0 & 3.0 & 0.0 & 0.0 \\
$14 \mathrm{R}$ & 91.7 & 1.7 & 2.7 & 2.3 & 0.0 & 1.3 & 0.3 & 0.0 \\
$15 \mathrm{R}$ & 76.7 & 1.3 & 2.7 & 12.7 & 0.0 & 6.7 & 0.0 & 0.0 \\
$16 \mathrm{R}$ & 77.3 & 2.3 & 2.0 & 14.0 & 0.0 & 4.3 & 0.0 & 0.0 \\
$17 \mathrm{R}$ & 61.0 & 13.7 & 3.3 & 13.0 & 0.0 & 3.7 & 0.3 & 5.0 \\
$18 \mathrm{R}$ & 66.0 & 0.7 & 1.0 & 16.0 & 0.0 & 3.0 & 1.3 & 12.0 \\
19R & 76.3 & 2.7 & 1.7 & 7.0 & 0.0 & 0.0 & 0.0 & 12.3 \\
20R & 5.7 & 6.0 & 6.7 & 13.7 & 11.0 & 47.3 & 2.3 & 7.3 \\
21R & 2.7 & 2.7 & 4.3 & 2.0 & 0.0 & 83.3 & 0.7 & 4.3 \\
22R & 1.0 & 1.7 & 9.0 & 8.3 & 1.7 & 71.3 & 3.3 & 3.7 \\
23R & 1.3 & 3.3 & 3.7 & 8.3 & 2.7 & 69.3 & 7.7 & 3.7 \\
\hline
\end{tabular}

Moluscos, briozoarios, algas calcáreas, pellets, oolitos, corales y equinodermos, foraminíferos, beach rock. 
Tabla 7. Imágenes satelitales utilizadas y su resolución (m).

\begin{tabular}{ccccc}
\hline Año & Sensor & Path/Row & Fecha & Resolución \\
\hline 1974 & L1 & $21 / 47$ & $15 / 02 / 1974$ & 60 \\
1976 & L2 & $20 / 46$ & $12 / 02 / 1976$ & 60 \\
1979 & L3 & $20 / 45$ & $05 / 02 / 1979$ & 60 \\
1988 & L4 & $22 / 47$ & $03 / 11 / 1988$ & 30 \\
1995 & L5 & $22 / 47$ & $27 / 03 / 1995$ & 30 \\
1996 & L5 & $21 / 47$ & $11 / 01 / 1996$ & 30 \\
2004 & L7 & $18 / 46$ & $12 / 12 / 2004$ & 30 \\
2005 & L7 & $21 / 47$ & $27 / 01 / 2005$ & 30 \\
2006 & L7 & $22 / 47$ & $22 / 02 / 2006$ & 30 \\
2014 & L8 & $21 / 47$ & $01 / 03 / 2014$ & 30 \\
2014 & L8 & $22 / 47$ & $08 / 03 / 2014$ & 30 \\
2014 & L8 & $18 / 46$ & $24 / 02 / 2014$ & 30 \\
\hline
\end{tabular}

de líneas de costa de las Figuras 6 a 11. Las imágenes L1, L2 y L3 se usan como referencia comparativa con los muestreos realizados para los años correspondientes y como una referencia visual en casos muy marcados, explicados y sustentados con información adicional por especialistas; sin embargo, no se puede hacer una comparación cualitativa o cuantitativa con las imágenes L4, L5, L7 y L8 ya que su resolución espacial es diferente. Los productos LANDSAT del nivel $1 \mathrm{G}$ proporcionan una precisión geométrica que cae dentro de los 30 y $60 \mathrm{~m}$, por lo tanto las diferencias entre las imágenes deberían ser mayores que un pixel para ser consideradas, cabe mencionar que para este estudio no se documentó el RMSE (error de la raíz cuadrada media) de cada imagen ya que la finalidad no es calcular tasas de erosión o acreción mediante percepción remota, sino establecer las líneas de costa.

\section{Resultados}

Las playas estudiadas en el presente trabajo están constituidas por dos poblaciones distintas de muestras: 1) las terrígenas (estaciones 1 a 11) y 2) las carbonatadas (12 a 23). Estas últimas se encontraron en dos regiones: 1) sur del Golfo de México (SGM) (estaciones 12 a 19), y 2) al norte del Caribe Mexicano o Riviera Maya (estaciones 20 a 23).

\subsection{Perfiles de Playa}

En el análisis de los perfiles de playa (Figuras 4, 5, 6) se tomaron en cuenta diversos parámetros que se consideró podían estar afectando a las playas, como son: la marea, la cual puede estar como cresta, descendente, valle y ascendente; la precipitación pluvial presente en la cuenca asociada con la playa, y la ubicación de las playas en relación a la desembocadura de ríos, presencia de escolleras o palizadas que se construyen como defensa contra la erosión.

\subsubsection{Tabasco}

En la Figura 4 se presentan los perfiles de playa tanto antiguas (A) como recientes (R) del área de Tabasco, así como el estado de las mareas durante el muestreo. En la Tabla 1 se presentan las fechas de colecta de las muestras, así como la posición exacta del punto de muestreo. Los perfiles antiguos de playas de Tabasco (1 a 10) se realizaron en mayo de 1981 y los recientes en septiembre de 2011. Las playas recientes de Tabasco, con excepción de Tonalá, son más extensas que las antiguas independientemente de las condiciones de marea.

\subsubsection{Campeche}

Campeche es uno de los cinco estados litorales del golfo de México y en él existe uno de los más ricos ecosistemas del país que es la Laguna de Términos (Yáñez-Arancibia et al., 1999).

En los perfiles de playas de Campeche (Figura 5), la precipitación mensual fue siempre mayor para las playas antiguas que para las recientes (Tabla 2). Con excepción de los perfiles recientes de las playas Canchec y Xochen (que se levantaron en septiembre de 2013) el resto de los perfiles recientes fueron de mayo de 2007. Los perfiles de las playas antiguas se levantaron en mayo de 1981 (Tabla 1).

El perfil de playa de Campechito pertenece a la Cuenca Deltaica de Tabasco (Figura 2) de sedimentos terrígenos, el resto de los ocho perfiles restantes localizados en Campeche, corresponden con playas de sedimentos carbonatados de colores claros según se vio en las descripciones de campo. Esto contrastaba con los muestreos de playas de Tabasco donde se observaban en campo arenas grisáceas terrígenas.

Las playas carbonatadas del estado de Campeche presentan anchuras distintas entre los muestreos antiguos y recientes; así, las playas de Bahamita, Isla Aguada, Sabancuy, Canchec y Xochen presentan una extensión menor en los muestreos antiguos, en tanto que las playas Playa Norte, Paso Real y Champotón presentan una mayor anchura en los muestreos antiguos.

La gran diferencia en extensión observada en la playa Bahamita (Figura 5, Playa 13), se asocia con la ubicación de las playas estudiadas en esta localidad. La menor extensión en la playa antigua de Sabancuy (Figura 5, Playa 16), se asocia con procesos de erosión en el área, y en las playas Canchec y Xochen (Figura 5, playas 17 y 18) la extensión se relaciona con la cantidad de lluvias presentes en la época del muestreo.

Las extensiones menores encontradas en playas recientes de Playa Norte (Figura 5, Playa 12), e Isla Aguada (Figura 5, Playa 15) se relacionan con la cantidad de sedimentos aportados por la boca occidental de la Laguna de Términos.

\subsubsection{Caribe Norte (Riviera Maya)}

En esta área se estudiaron cuatro localidades de playa. El perfil antiguo de Cancún fue realizado antes del huracán Gilberto (1988) y el reciente se colectó después de los huracanes Gilberto y Vilma (2005), posterior a la reconstrucción. El perfil de 1982 (Tabla 1) se hizo cuando la marea estaba en cresta y el de febrero de 2013 en valle. 


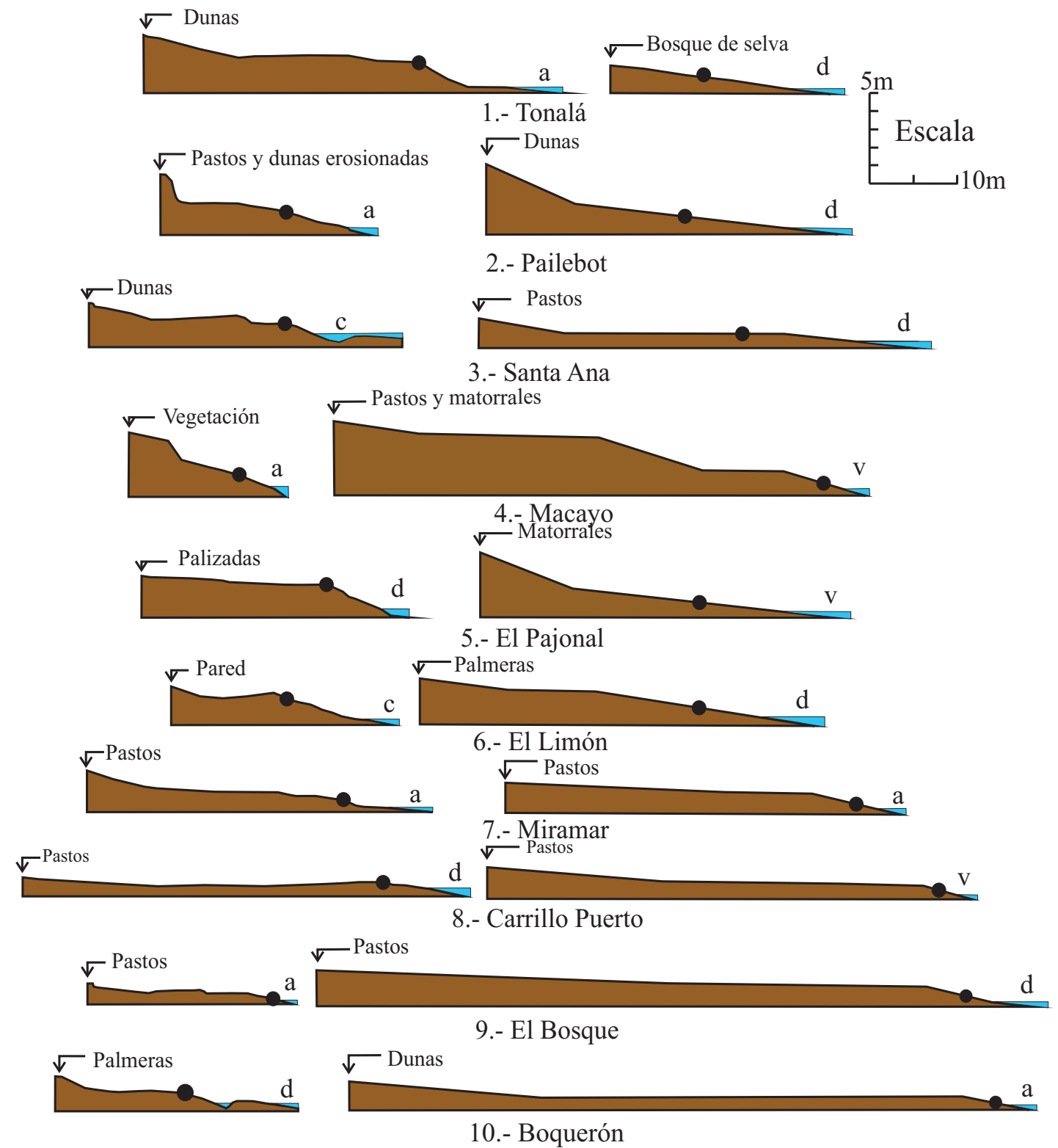

Figura 4. Perfiles de playa del estado de Tabasco. A la izquierda aparecen perfiles antiguos y a la derecha perfiles más recientes. El círculo corresponde con la ubicación de la muestra superficial colectada en el frente de playa. El estado de la marea está representado por $\mathrm{c}=\mathrm{cresta}, \mathrm{d}=\mathrm{descendente,} \mathrm{v}=$ valle y a $=$ ascendente. En color pardo los perfiles de playas con arenas terrígenas.

Las lluvias mensuales (Tabla 2) promediadas son de 101 mm para Cancún y de $26 \mathrm{~mm}$ para Puerto Morelos. La playa reciente de Puerto Morelos era ligeramente más ancha, pero la marea se encontraba en el valle de la onda de marea.

Playa del Carmen contaba en 1971 con un perfil de playa muy bien desarrollado a pesar que la marea estaba en ascenso y que pudo cubrir parte del frente de playa (Figura 6 , Playa 22).

En el caso de Playa Akumal ambos perfiles son cortos (10 m el antiguo y $25 \mathrm{~m}$ el reciente) y con pendientes similares. El perfil más reciente es un poco más extenso pero la marea está en el valle de la onda.

\subsection{Textura de los sedimentos}

\subsubsection{Tabasco}

El tamaño gráfico promedio (Mz申) de los sedimentos litorales terrígenos del estado de Tabasco (Figura 7) fluctúa desde arenas medias al oeste hasta arenas finas al este. Los ríos principales que aportan estos terrígenos son de oeste a este: Tonalá, González, Grijalva y San Pedro-San Pablo (Figura 1). Los dos últimos son parte del sistema GrijalvaUsumacinta que constituyen los ríos más caudalosos del país y que proceden de tierras altas del Cinturón Chiapaneco (Figura 2). El relieve de las cuencas Grijalva y Usumacinta así como su pluviosidad es una razón para que el aporte en 

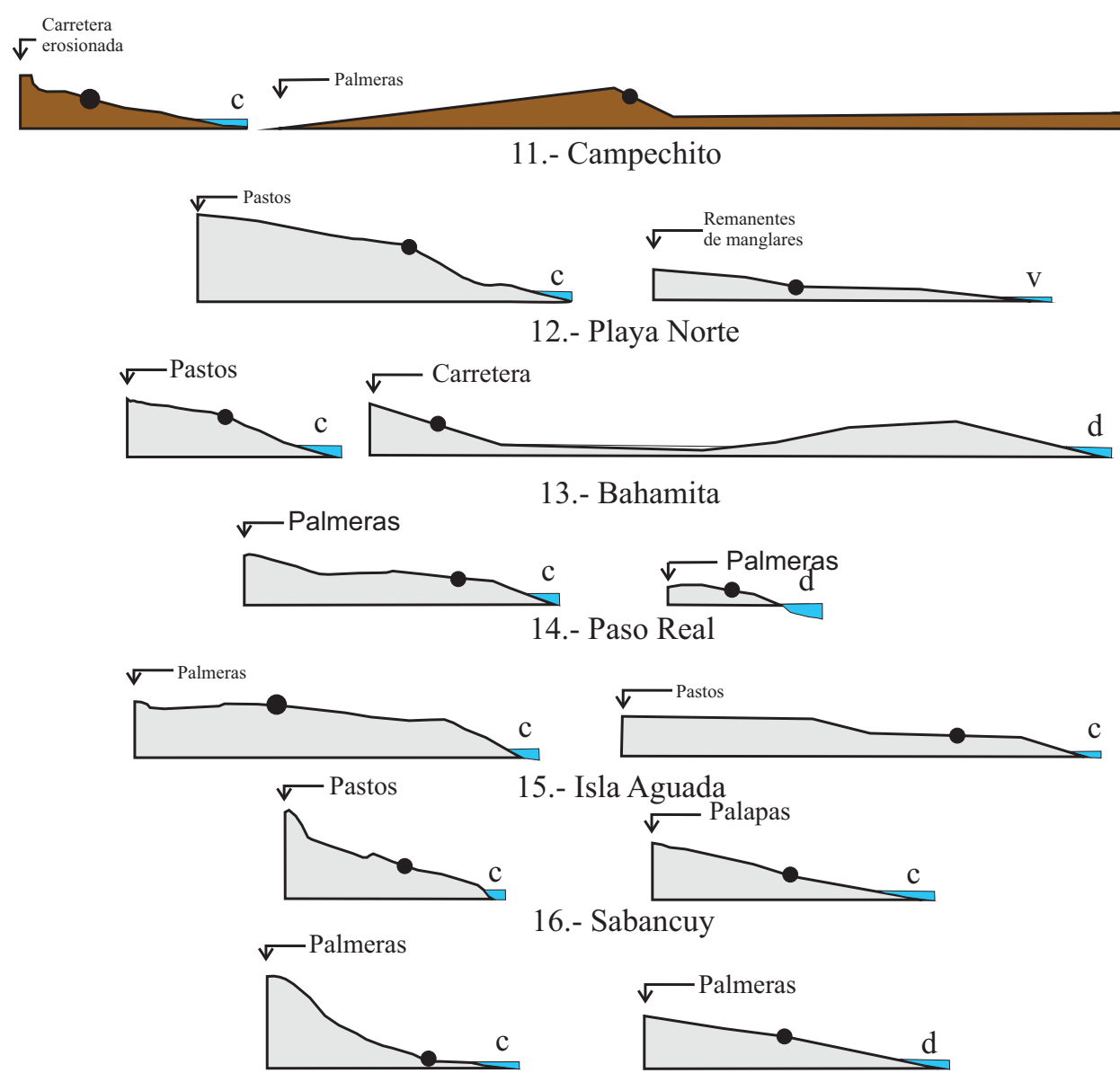

17.- Canchec
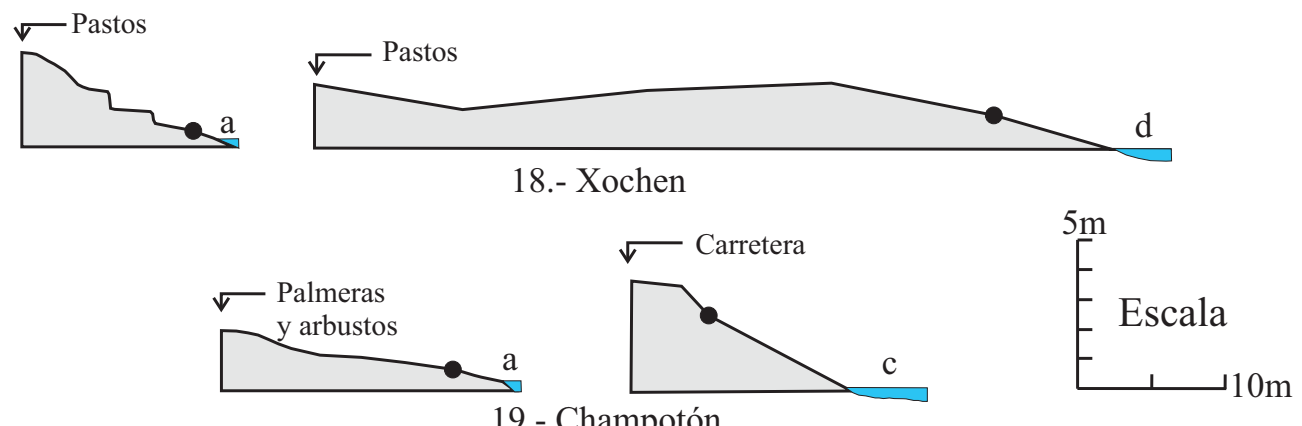

Figura 5. Perfiles de playa del estado de Campeche. A la izquierda aparecen perfiles antiguos y a la derecha perfiles más recientes. El círculo corresponde con la ubicación de la muestra superficial colectada en el frente de playa. El estado de la marea está representado por $\mathrm{c}=\mathrm{cresta}, \mathrm{d}=\mathrm{descendente}, \mathrm{v}=\mathrm{valle}$ y a $=$ ascendente. En color pardo el perfil de playa con arenas terrígenas y en gris muy claro los perfiles de playas de arenas carbonatadas.

las playas sea de sedimentos finos.

\subsubsection{Campeche}

Los rangos de variación de tamaños de partículas en los sedimentos terrígenos estudiados no son grandes, lo que hace que las muestras antiguas (triángulos) y las recientes (círculos) sean muy parecidas (Figura 7). En cambio, se establecen fuertes diferencias entre la clasificación de las partículas antiguas y recientes. En cuanto a la asimetría o sesgo llama la atención que la mayoría de los sedimentos recientes sean más asimétricos hacia los tamaños finos, a diferencia de los antiguos. El grado de curtosis es bastante parecido en la mayoría de las muestras antiguas y recientes.

\subsubsection{Riviera Maya}

El tamaño de partícula de las muestras de la Riviera Maya es similar a las muestras carbonatadas de Campeche, observándose una tendencia a una pobre clasificación con menor dispersión. Las muestras recientes presentan valores asimétricos hacia finos y muy finos, en tanto que las antiguas 


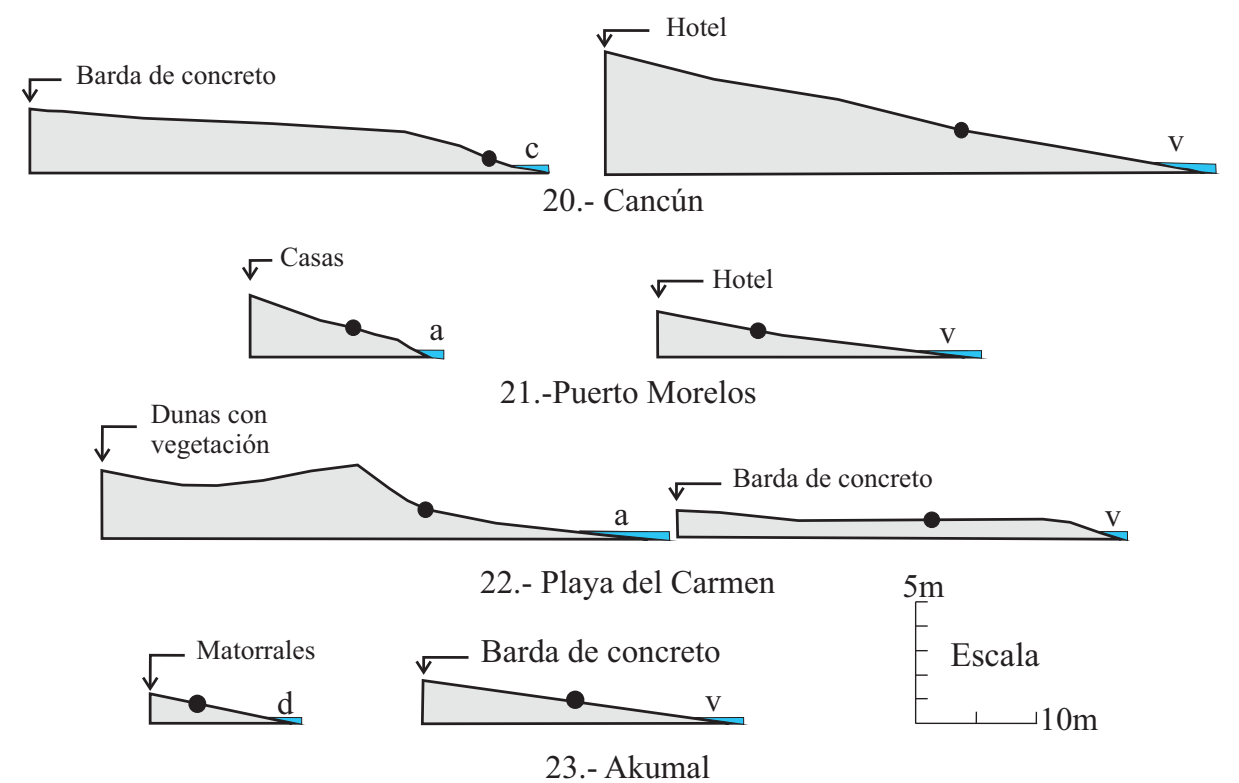

Figura 6. Perfiles de playa del estado de Quintana Roo. A la izquierda aparecen perfiles antiguos y a la derecha perfiles más recientes. El círculo corresponde con la ubicación de la muestra superficial colectada en el frente de playa. El estado de la marea está representado por $\mathrm{c}=\mathrm{cresta}, \mathrm{d}=\mathrm{descendente}, \mathrm{v}=$ valle y a $=$ ascendente. En color gris muy claro los perfiles de playas con arenas carbonatadas.

tienden a valores más asimétricos hacia tamaños gruesos, los valores de curtosis (Figura 7) tienden a ser similares a los observados en las otras regiones.

La dispersión de tamaños de los sedimentos carbonatados del sur del Golfo de México es mayor, más pobremente clasificados y tienen una mayor tendencia de muestras simétricas que en los sedimentos terrígenos, siendo más comunes las muestras mesocúrticas y leptocúrticas.

\subsection{Composición de las arenas}

\subsubsection{Sedimentos Terrígenos}

Por medio del microscopio petrográfico y a través del uso de láminas delgadas se determinó la cantidad de minerales pesados (MP) presentes en las muestras de sedimento (Figura 9). En la Figura 9a se aprecia que las playas recientes $6 \mathrm{R}$ (El Limón), 9R (El Bosque) y la playa antigua 5A (El Pajonal) tienen valores altos de minerales pesados $(35-60 \%)$ lo que sugiere un alto nivel de energía, asociado probablemente a condiciones de tormentas.

Previo al análisis composicional se hizo el conteo de partículas biogénicas al microscopio (Figura 8a) y la determinación de carbonatos por análisis químico (Figura $8 b$ ) con la finalidad de comprobar el análisis megascópico de las arenas en ejemplar de mano. Como se aprecia en la Figura 8a, la concentración de biógenos presenta un contraste entre los sedimentos terrígenos y los carbonatados, siendo considerablemente más alta la concentración de biógenos en las muestras carbonatadas. El límite está definido entre las playas Campechito (Camp.) de la estación 11 y de Playa Norte de la estación 12. Desde Playa Norte hasta Akumal (estación 23) en el estado de Quintana Roo, el contenido de biógenos incrementa de oeste a este de manera sostenida, para encontrarse cerca del $100 \%$ en la Riviera Maya.

\subsubsection{Sedimentos Carbonatados}

De acuerdo con los componentes, descritos en lámina delgada (Tabla 6), se observa que los sedimentos más recientes del sur del Golfo de México, están más enriquecidos en restos de moluscos y más empobrecidos en pellets si se les compara con los muestreados 26 años antes para las estaciones $12,13,14,15,16$ y 20 (Tabla 1) y 32 años para las estaciones 17 y 18 .

Para el caso de la Riviera Maya (Figura 9b) que cubre las playas $20,21,22$ y 23 se observa una disminución considerable de pellets para las playas recientes, sobre todo para las playas de Puerto Morelos (estación 21) y Playa del Carmen (estación 22), donde hay un gran incremento de la población urbana y los retrocesos de la línea de costa son pequeños, como se observa en las Figuras 14 y 15.

\subsection{Líneas de Costa}

En la Tabla 7 se presentan las fechas de las imágenes utilizadas y los tipos de sensores que se usaron para el análisis de las variaciones de la línea de costa. Se eligieron dos casos representativos por estado (Tabasco, Campeche y Quintana Roo). La precisión de las imágenes LANDSAT recientes responde a una resolución de $30 \mathrm{~m}$ por $30 \mathrm{~m}$, en tanto que en las antiguas es de $60 \mathrm{~m}$ por $60 \mathrm{~m}$, lo cual se aprecia en los contornos de líneas de costa de las Figuras 10 a 15; sin embargo, se logran observar diferencias en la ubicación de la línea de costa. 

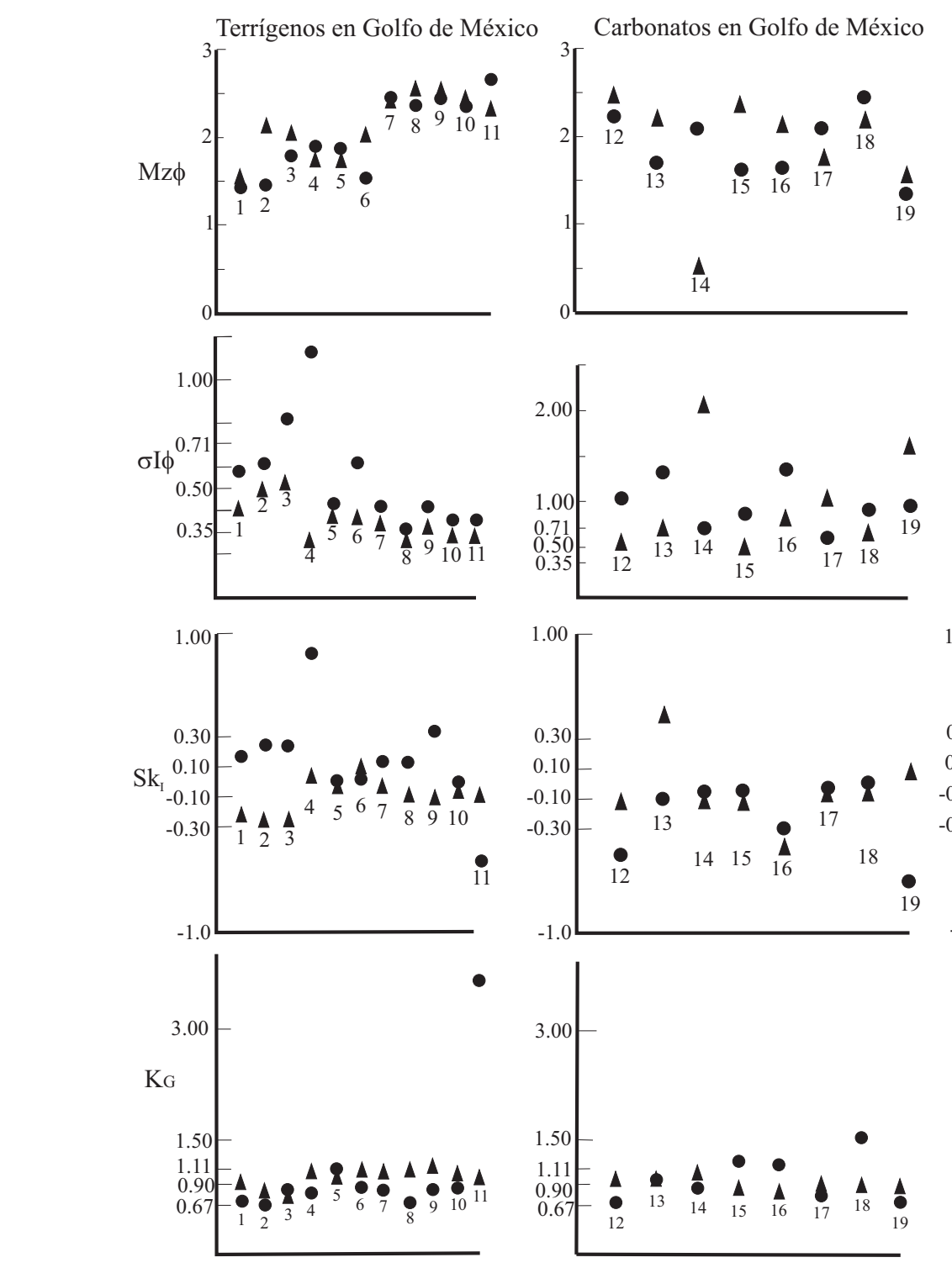

Carbonatos en Riviera Maya
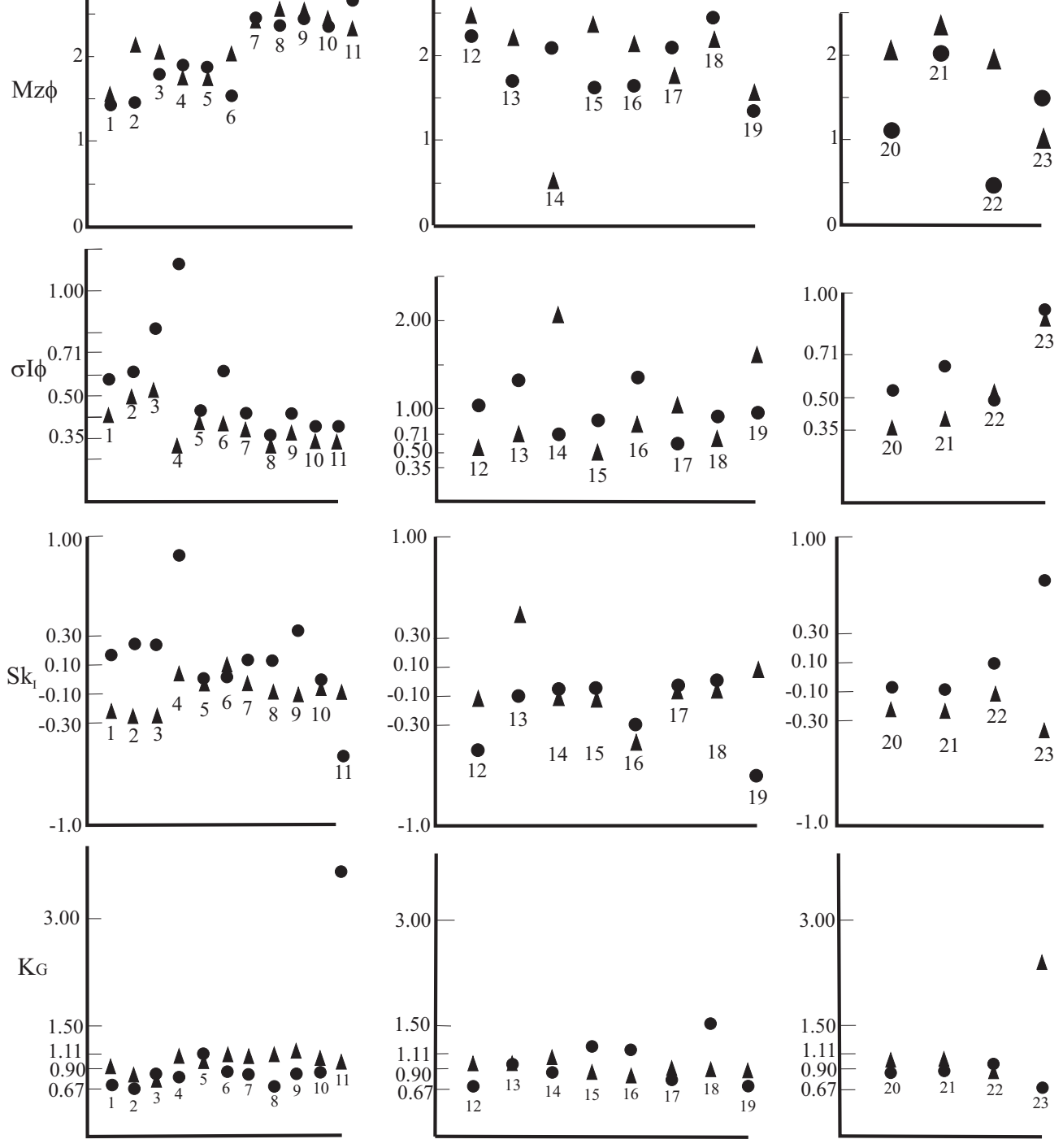

Estaciones de muestreo

Figura 7. Los parámetros texturales de los sedimentos del frente de playa, obtenidos con las fórmulas sugeridas por Folk (1980). Mzф $=$ tamaño gráfico promedio, $\sigma \mathrm{I} \phi=$ desviación estándar gráfica inclusiva, $\mathrm{SkI}=$ simetría, $\mathrm{KG}=$ curtosis. Arenas de muestreos antiguos (triángulos) y recientes (círculos).

A través de los mapas de líneas de costa elaborados a partir de imágenes satelitales de distintas fechas, se pueden interpretar las diferencias en longitud de perfiles playeros y su relación con procesos de erosión/sedimentación que ocurren en amplios periodos de tiempo. Incluso con pequeñas diferencias en la distancia entre estaciones de muestreo se pueden encontrar grandes diferencias entre las diversas posiciones de las líneas de costa, como sucede en playas cercanas al río Grijalva (Tamayo, 1990).

En el presente trabajo se estudiaron en detalle las variaciones de línea de costa en seis localidades, dos localidades correspondientes a cada una de las áreas estudiadas. En las playas terrígenas de Tabasco se elaboró la línea de costa antigua y reciente de las playas El Limón, (Playa 6, Figura 10) y de la playa El Bosque (Playa 9, Figura
11). De las playas de Campeche se elaboró la línea de costa antigua y reciente de Playa Norte (Playa 12, Figura 12) y de la playa Champotón (Playa 19, Figura 13). En la zona de la Riviera Maya se elaboraron los perfiles de playa antiguos y recientes de las playas de Puerto Morelos (Playa 21, Figura 14) y de playa del Carmen (Playa 22, Figura 15).

\section{Discusión}

\subsection{Playas terrígenas del sur del Golfo de México}

Con el objeto de explicar las diferencias en morfología y extensión entre las playas antiguas (A) y recientes (R), se tomó en cuenta el efecto de diversos parámetros como 


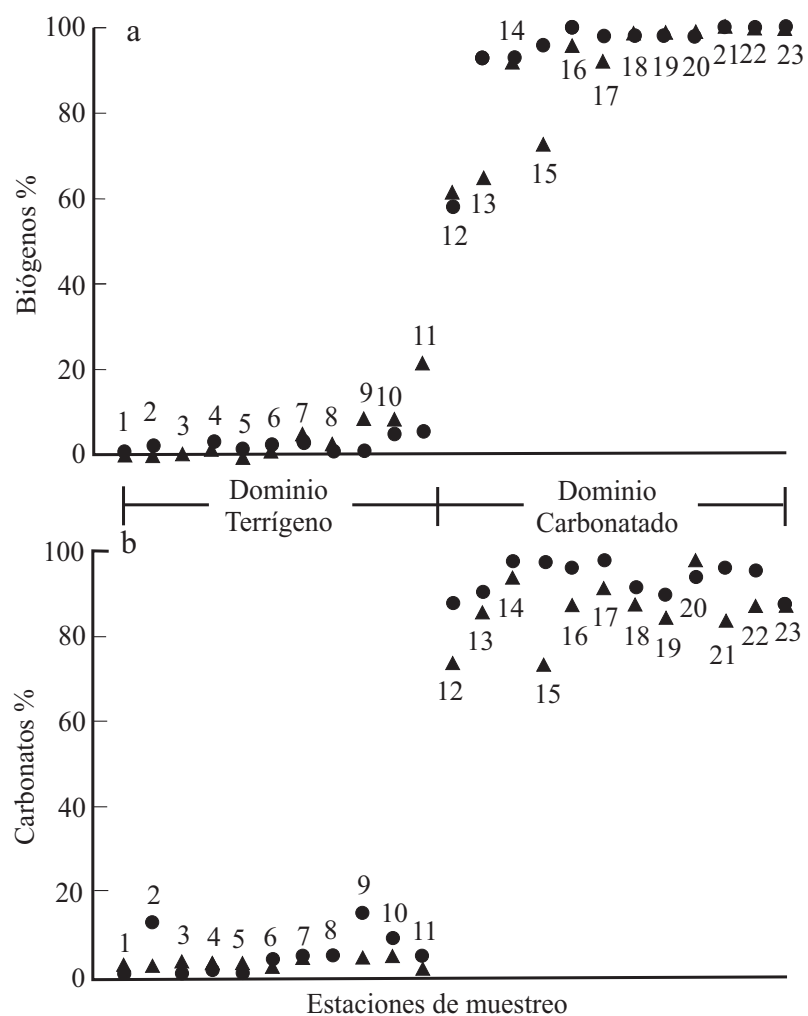

Figura 8. a) Porcentajes de biógenos y b) porcentajes de carbonatos para los muestreos antiguos (triángulos) y recientes (círculos).
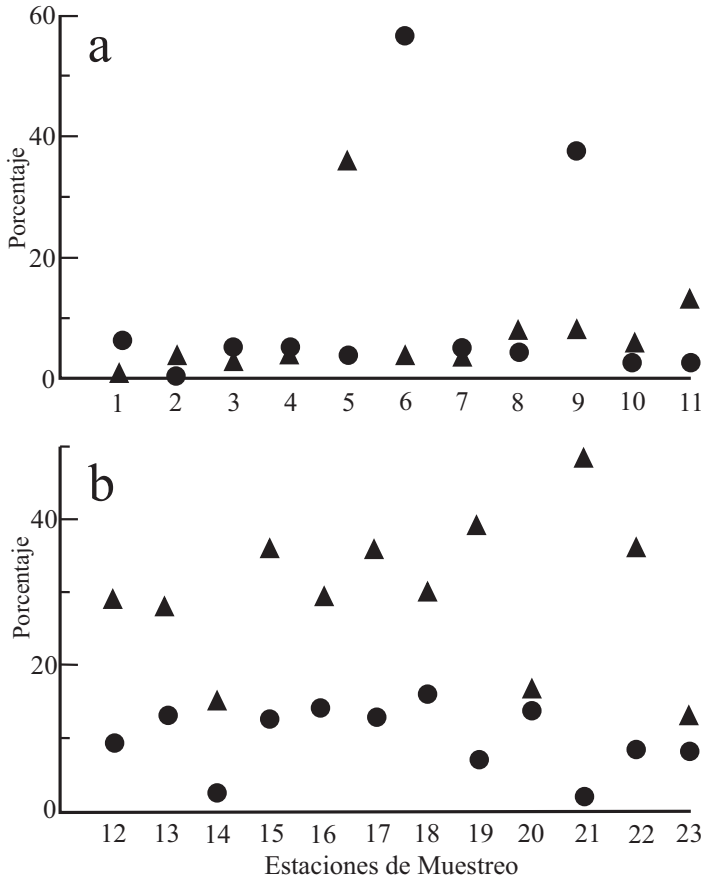

Figura 9. Análisis modal con microscopio petrográfico en lámina delgada. Para terrígenos se utilizó (Figura 9a) la concentración de minerales pesados (MP) y para sedimentos carbonatados (Figura 9b) los pellets. Para ambos casos esos constituyentes tuvieron mayor peso estadístico por componentes principales. Mayores detalles petrográficos se encuentran en la Tabla 4. Muestreos antiguos (triángulos) y recientes (círculos).

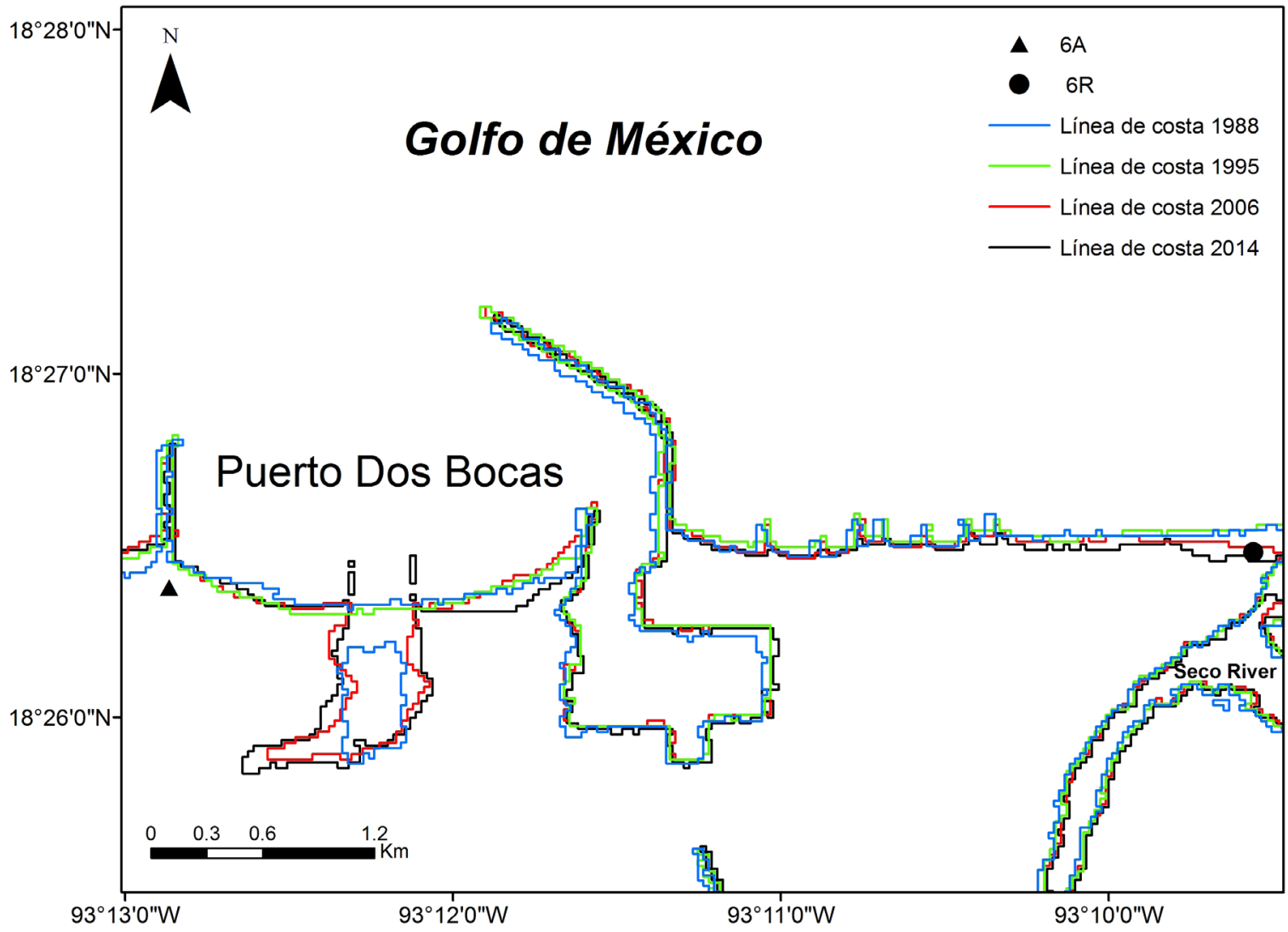

Figura 10. Líneas de costa para la playa El Limón, Tabasco. El triángulo representa la posición del muestreo antiguo y el círculo el muestreo reciente. 


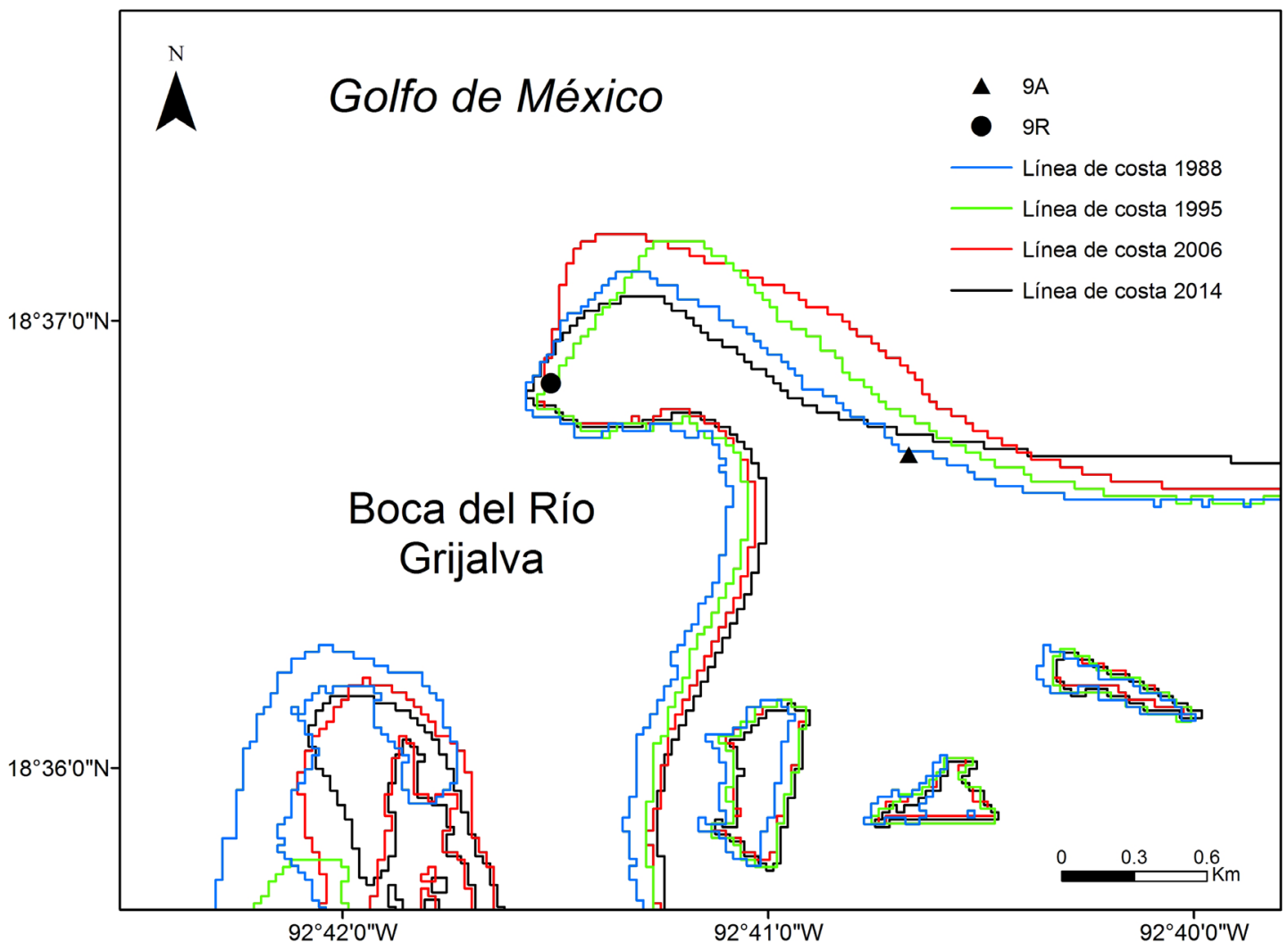

Figura 11. Líneas de costa para la playa El Bosque, Tabasco. El triángulo representa la posición del muestreo antiguo y el círculo el muestreo reciente.

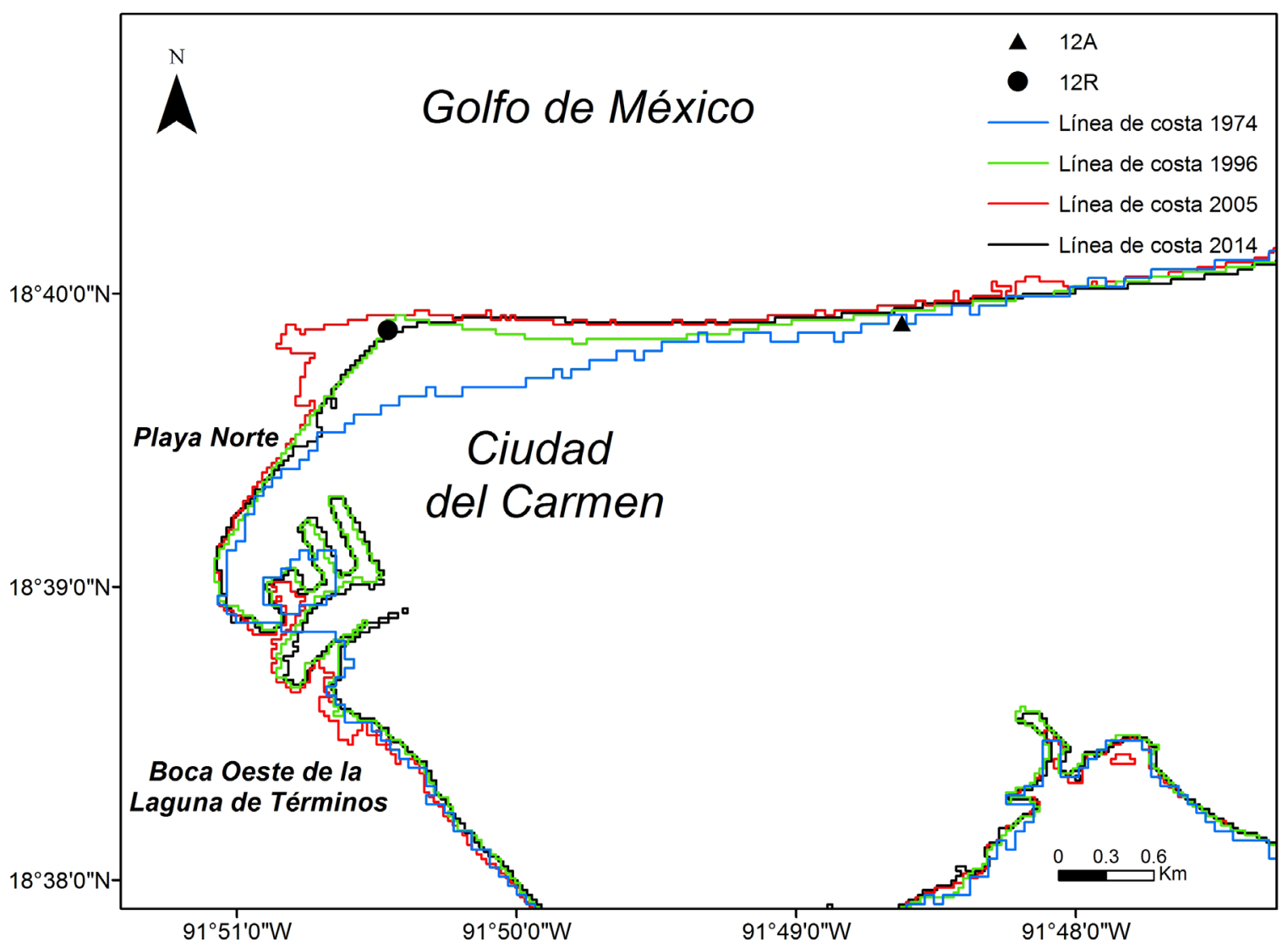

Figura 12. Líneas de costa para Playa Norte, Campeche. El triángulo representa la posición del muestreo antiguo y el círculo el muestreo reciente. 


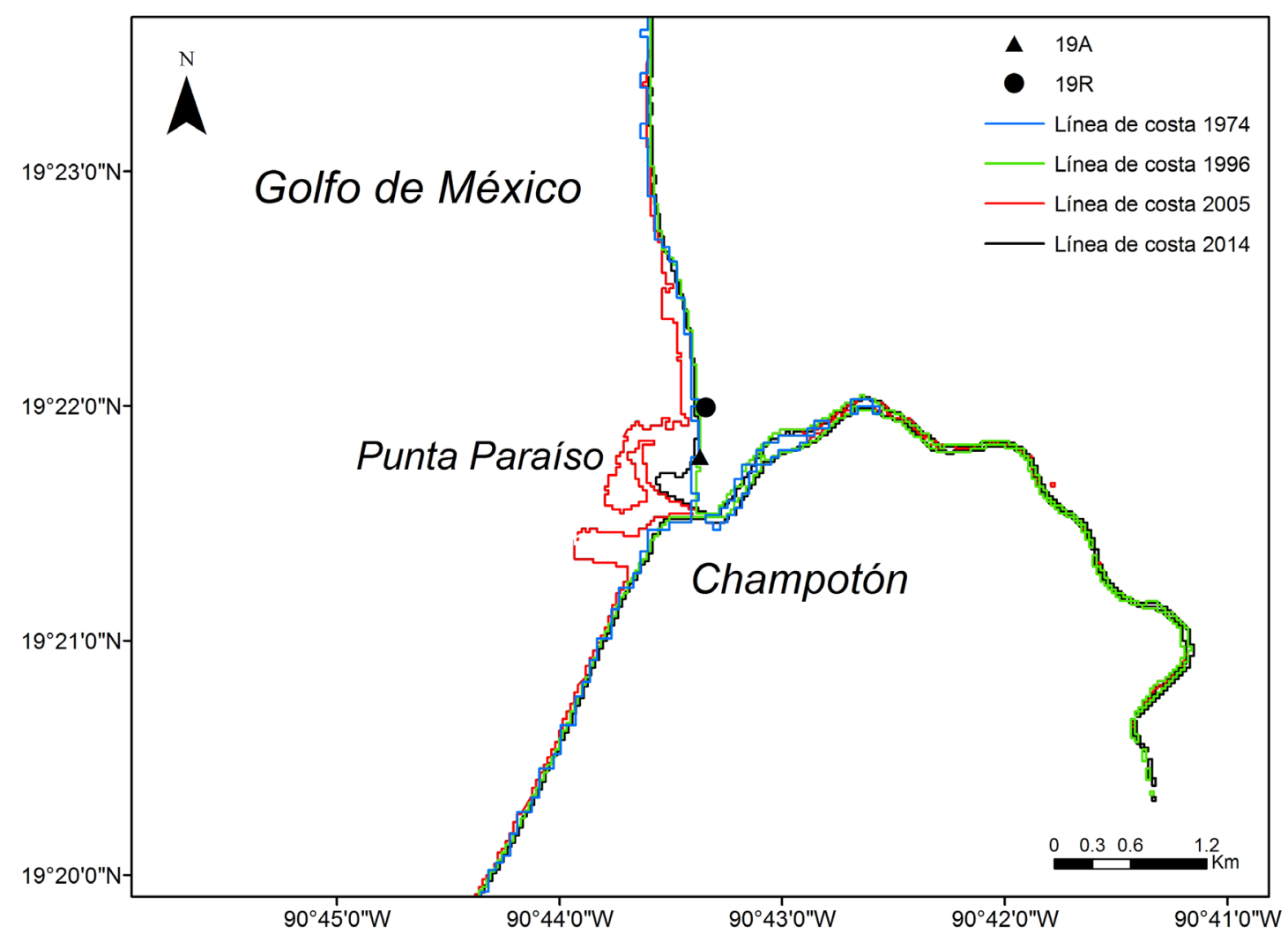

Figura 13. Líneas de costa para la playa de Champotón, Camp. El triángulo representa la posición del muestreo antiguo y el círculo el muestreo reciente.

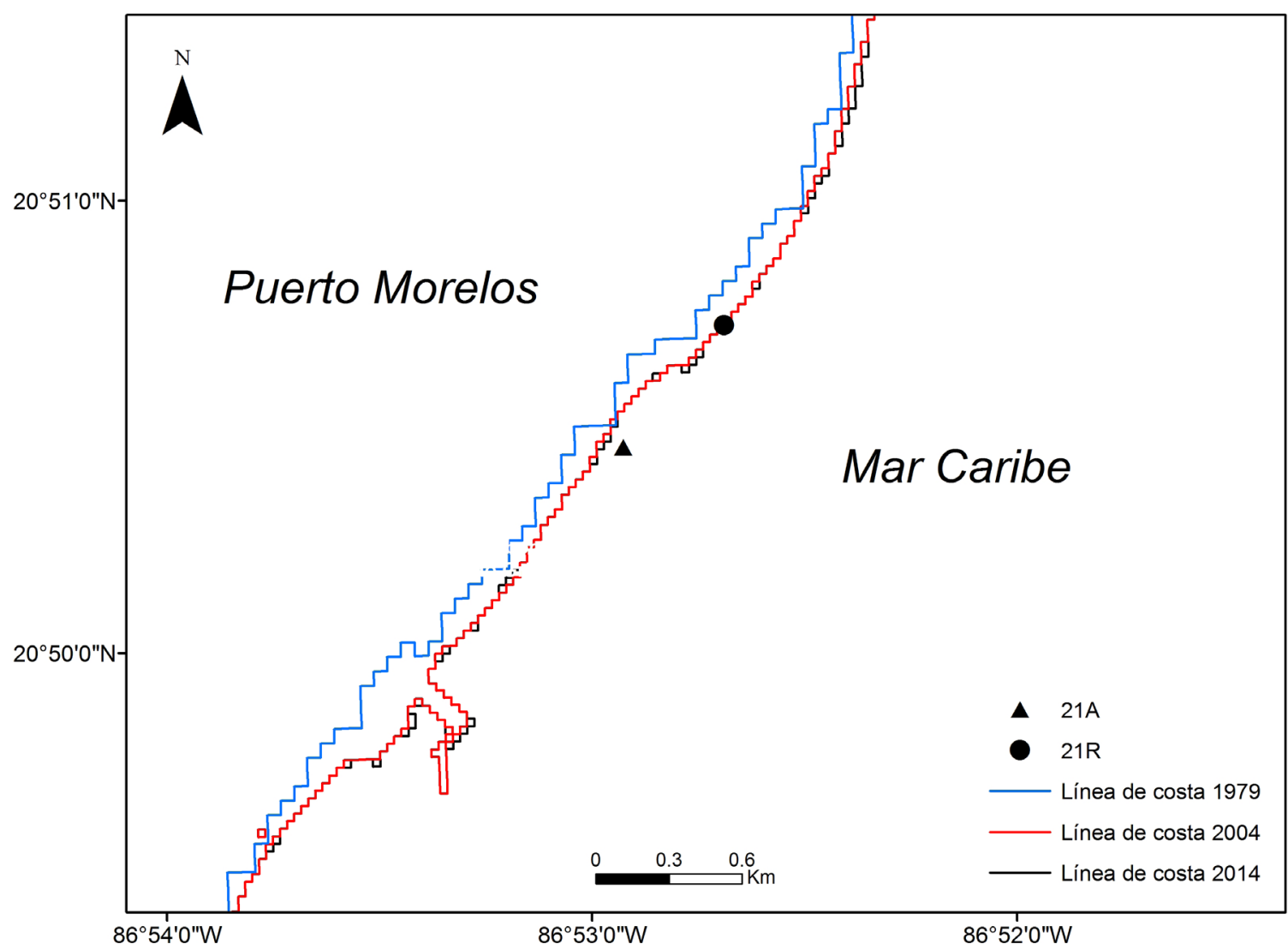

Figura 14. Líneas de costa para la playa de Puerto Morelos, Q. Roo. El triángulo representa la posición del muestreo antiguo y el círculo el muestreo reciente. 


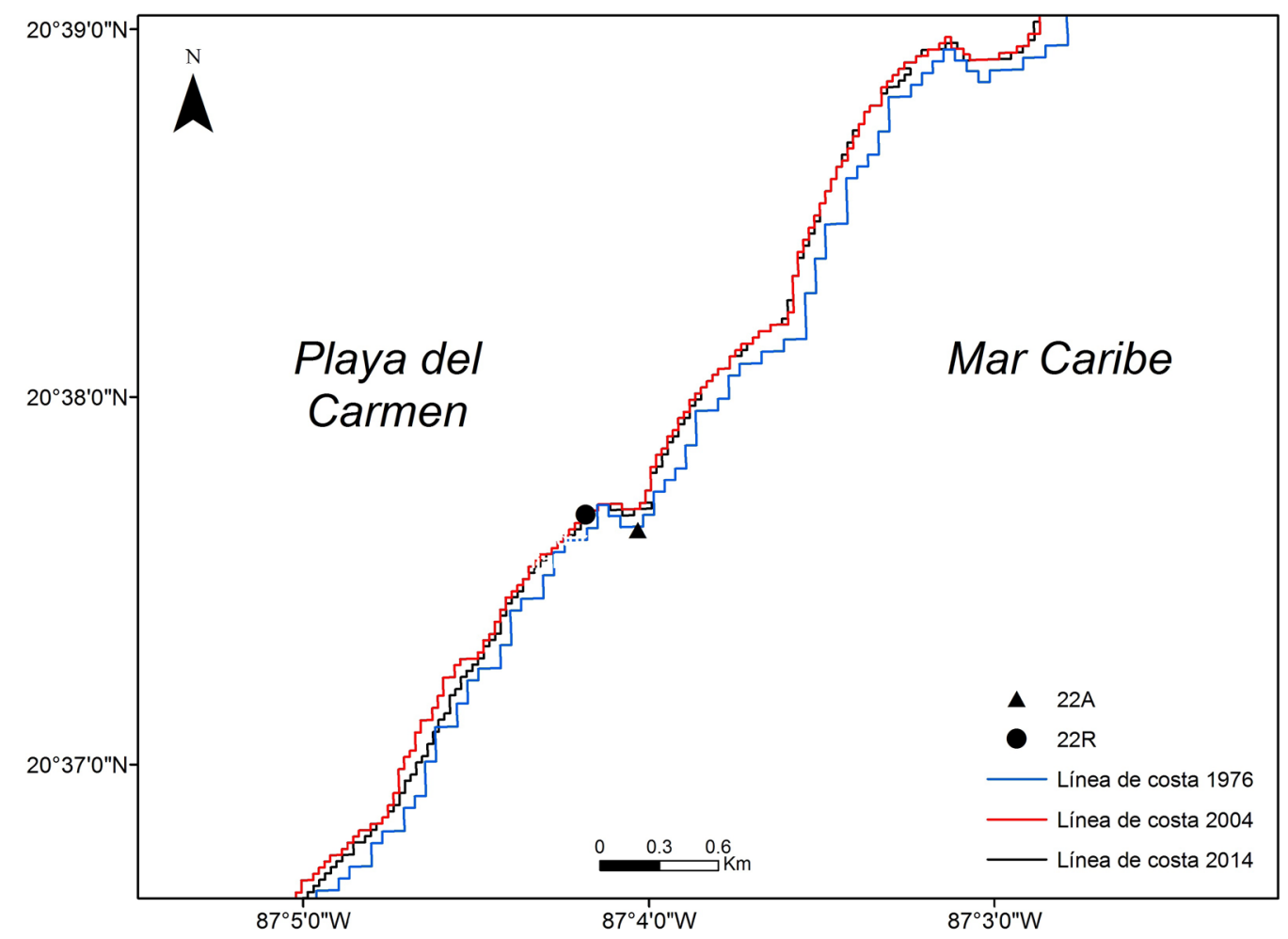

Figura 15. Líneas de costa para la playa de Playa del Carmen, Q. Roo. El triángulo representa la posición del muestreo antiguo y el círculo el muestreo reciente.

son la marea, la precipitación y la ubicación de las playas. Aparentemente la marea prevaleciente en el momento del muestreo no afecta la extensión de la playa, por ejemplo en la playa de Miramar (Playa 7, Figura 4), la marea era ascendente durante ambos muestreos, la playa reciente es más ancha que la playa antigua.

La precipitación pluvial puede tener un efecto en la extensión de las playas, ya que a mayor pluviosidad corresponderá una mayor carga de sedimentos procedentes del continente por vía fluvial. Las precipitaciones están influidas por grandes eventos hidrometeorológicos cercanos y previos a las fechas de los muestreos, dado que los muestreos antiguos se hicieron en mayo de 1981 y los muestreos recientes en septiembre de 2011, cercanos a la época de lluvias en la cuenca (julio/agosto). Cabe señalar que en septiembre de 2011 llovió cerca del doble, comparado con los datos del muestreo de playas antiguas (Tabla 2), lo que podría explicar el incremento de la longitud de playa por el aporte de sedimentos por parte de los ríos en el muestreo realizado en época reciente.

Existe la posibilidad de que la erosión se asocie con fenómenos de subsidencia (Yuill et al., 2009), derivada quizá de la extracción de fluidos del subsuelo, lo cual también ha sido sugerido por Carranza-Edwards (2010). No obstante, en un mapa de 1808 publicado en West et al. (1976), se menciona que el extremo occidental del estado de Campeche es un "lodazal", por lo que es posible suponer que, a lo largo del tiempo, la influencia de sedimentos finos no permite la estabilización de ese segmento, lo cual ya ha sido mencionado por Tanner et al. (1971) quienes señalan la importante existencia de procesos erosivos en esta porción litoral y el elevado retroceso de la línea de costa para Punta Disciplina, localizada a unos $50 \mathrm{~km}$ al este de la decimoprimer estación, calculado en $700 \mathrm{~m}$ desde el año 1974 hasta el 2008 por Torres-Rodríguez et al. (2011).

Aún cuando han ocurrido en el sur del Golfo de México numerosos eventos (Figura 3) hidrometeorológicos (noventa y cinco desde 1851 hasta 2013), los que resultan más importantes considerar, para la anchura de los perfiles de playa, son los inmediatos anteriores a la fecha de la construcción del perfil, dada la enorme cantidad de sedimentos aportados durante las tormentas relacionadas con dichos eventos. Con el tiempo el perfil de playa tenderá a restaurarse de manera natural, cuando la erosión se encargue de remover los sedimentos más finos hacia mar adentro.

Las extensiones de playa muestran que Tonalá (Figura 4, playa 1), es la única playa antigua más extensa que la playa reciente, probablemente asociado con oleaje de verano de baja energía que favorece una mayor depositación. En el caso de Pailebot (Playa 2, Figura 4) se aprecia un perfil reciente de tipo cóncavo que puede implicar erosión, aunque la marea se encuentra en descenso en el muestreo reciente, esta es diurna y de rangos menores a un metro, por lo que la extensión de la playa no se atribuye a un efecto de la marea 
sino más bien a la influencia de descargas de sedimentos de la Boca de la Laguna del Carmen. Un comportamiento similar se da para el perfil de Santa Ana (Playa 3, Figura 4), la cual en el perfil antiguo se hizo un poco más cercana a la escollera de Sánchez Magallanes que impide el depósito de sedimentos, no así el perfil reciente que se ubica más al oeste de dicha escollera.

El gran contraste en anchura entre el perfil reciente y el antiguo de Macayo (Playa 4, Figura 4) se debe a que el perfil reciente se realizó al este de la misma escollera y un poco más cercano a la boca $(160 \mathrm{~m})$, en comparación con el antiguo $(1800 \mathrm{~m})$, de esta manera la escollera actúa como retenedora de los sedimentos del mes lluvioso de septiembre de 2011.

Más al este se ubican los perfiles de la localidad de El Pajonal (Playa 5, Figura 4), el cual se presenta cóncavo en el perfil reciente y convexo en el antiguo, lo que podría significar un evento erosivo reciente, no obstante que el perfil reciente se realizó cuando había más precipitación (242 mm de septiembre de 2011 vs. $129 \mathrm{~mm}$ de mayo de 1981). Ya desde 1981 había erosión considerando que el límite de la supra playa estaba dado por palizadas que se usaban como defensa contra la misma. Sólo la muestra antigua de la playa El Pajonal (5 A), resultó tener una mayor concentración de minerales pesados que la muestra reciente, esto se explica por la mayor pendiente del perfil antiguo de playa que la del perfil reciente, lo que parece indicar una mayor energía del oleaje para esa época de muestreo, teniendo en ese caso una mayor estabilidad para las partículas de mayor peso o de mayor densidad como sucede con los minerales pesados (Roy, 1999).

Castellanos-Trujillo (1992) reporta, a través de un compósito de cinco playas, la presencia de minerales pesados en playas de este de Tabasco y oeste de Campeche, entre los cuales reporta por difracción de rayos X la presencia de ilmenitas, magnetitas, piroxenas, cromita y zircón.

Para la playa El limón (Playa 6, Figura 4), se observa que el perfil reciente tiene casi el doble de amplitud que el antiguo y en este caso el efecto de marea no tendría gran importancia porque aunque en El Limón la marea está en descenso, en el reciente y en el antiguo se encuentra en su cresta, y dada la pendiente de ambos perfiles no se esperaría un cambio importante en la extensión de dichos perfiles. Las muestras recientes de la playa El Limón son más ricas en minerales pesados que sus correspondientes antiguas (Figura 9), esto se explica por mayores condiciones de energía, que permiten que los minerales de mayor densidad permanezcan en las playas y esto comúnmente se relaciona con erosión costera (Ergin et al., 2007). La erosión de aproximadamente $200 \mathrm{~m}$ que se ha presentado en la estación 6R (Figura 10), pudo haber dado lugar al incremento en minerales pesados, los cuales son más resistentes a la erosión, y se podría relacionar con la construcción de la escollera oeste del Puerto de Dos Bocas, que puede desviar los sedimentos litorales un poco hacia el norte. En el análisis de variación de la línea de costa de la playa El Limón se observa que el muestreo antiguo (estación 6A) se ubica por detrás de la línea de costa de 1988 (Figura 10). Esto se debe a la acumulación de sedimentos usados para la construcción del Puerto Dos Bocas en el Golfo de México, ya que la posición de la estación $6 \mathrm{~A}$ coincide con la escollera oeste del Puerto de Dos Bocas. Esta relativa progradación se debe a las actividades antrópicas posteriores al año 1981. En el muestreo reciente (6R), la estación se ubica cerca del río Seco, apreciándose un retroceso de la línea de costa de un poco menos de $200 \mathrm{~m}$ al comparar la línea de costa de 1988 contra la de 2014. En el caso del muestreo reciente (6R) las líneas de costa de 1988 y de 1995 presentan avance al mar como un posible exceso de sedimentación por los huracanes Gilberto y Opal (Tabla 8); en cambio, la línea de costa de 2014 sí refleja un retroceso por posible erosión litoral, debida tal vez a la acción de los nortes más que al aumento del nivel del mar por cambio climático, ya que las elevaciones de éste son del orden de $5 \mathrm{~cm}$ en los últimos 30 años de acuerdo con Church et al. (2013).

La playa Miramar (Playa7, Figura 4) muestra un perfil ligeramente mayor en el muestreo reciente explicable por la influencia de la época de lluvias.

En Carrillo Puerto (Playa 8, Figura 4) ambos perfiles son amplios y similares, lo que se debe a la cercanía del nuevo canal que se abrió al oeste de la desembocadura del río Grijalva que es un gran aportador de sedimentos.

El perfil reciente de la playa El Bosque (Playa 9, Figura 4) está justo en la desembocadura del río Grijalva y el perfil antiguo se ubica un poco más al este $(1500 \mathrm{~m})$ de dicha desembocadura. En este caso juega un papel muy importante la precipitación por ser responsable de una mayor sedimentación para septiembre de 2011 que para mayo de 1981 (Tabla 2). El contenido de minerales pesados en la playa reciente de El Bosque (Playa 9R) es mayor que en el muestreo antiguo, ya que la estación antigua se ubica a unos $1800 \mathrm{~m}$ al este de la reciente, la cual prácticamente se encuentra en la desembocadura del río Grijalva. Generalmente en la boca de los ríos, la energía de oleaje acentúa considerablemente la energía del ambiente que actúa sobre la playa, lo que podría explicar la concentración de minerales pesados cuya presencia se ve reflejada también en el tamaño de partícula (Tabla 4) y asimetría (Komar y Wang, 1984).

En esta playa (El Bosque, 9 A) se han producido diversas líneas de azolve (Figura 11), lo que a su vez puede implicar que al este de la playa antigua ha existido erosión, sobre todo si se considera que el transporte litoral dominante es de este a oeste, se observa que después del muestreo antiguo (9A) la línea de costa se acrecienta para los años 1995 y 2006 cerca de $200 \mathrm{~m}$ y $250 \mathrm{~m}$ respectivamente, para posteriormente en el año 2014, retroceder a sólo unos $150 \mathrm{~m}$ del punto antiguo (9 A). La progradación que tuvo efecto durante 1995 pudo ser resultado de un exceso de sedimentación producido por influencia del huracán Gilberto (NOAA, 2014) el cual tocó tierra en Cancún el 14 de septiembre de 1988. Por otro lado, 
la línea de costa de 2005 pudo ser una respuesta a la gran sedimentación provocada en el Golfo de México en octubre de 2005 por el huracán Wilma (Tabla 8).

La muestra reciente de esta playa (9R), obtenida en 2011 (Tabla 1) no presenta tantas variaciones a lo largo del tiempo, no obstante, se observa que la línea de 1988 retrocede ligeramente hacia 1995 y avanza hacia el 2006 casi traslapándose con las correspondientes a los años 1988 y 2014. De cualquier forma el muestreo del 2001 (9R) parece ser similar al de 1995.

La margen izquierda del río Grijalva se ha reducido si se compara la posición de la línea de costa de 1988 con la del 2014 (Figura 11), probablemente provocado por la apertura del canal de navegación Santa Elena, que se abrió artificialmente y por la presencia de un espigón al Noreste de dicho canal.

Los perfiles de playa Boquerón (Playa 10, Figura 4) están muy próximos entre sí (circa $100 \mathrm{~m}$ ) y en ellos se observa una enorme diferencia de la amplitud de la playa. Las diferencias en la precipitación de mayo a septiembre puede ser la explicación, por lo tanto la precipitación sería responsable de tal ensanchamiento para el perfil reciente. Ambos perfiles están a unos cinco kilómetros de la desembocadura de un tributario del Grijalva que desemboca $24 \mathrm{~km}$ al oriente de este último. Esto reforzaría de nuevo la idea de que el transporte litoral dominante es de este a oeste, como se ha reportado por Marín-Guzmán y CarranzaEdwards (2011) y Fernández-Eguiarte et al. (1992a) quienes indican una dominancia de las masas de aguas superficiales en la misma dirección para el verano.

El perfil antiguo de Campechito (Playa 11, Figura 5) es más corto que el perfil más reciente. En ambos casos el perfil se realizó cuando la onda de marea se encontraba en la cresta y además durante los muestreos se observó la presencia de erosión en la línea de costa, la cual diseccionó la mitad de la carretera federal en esa localidad. El hecho de que sea más largo el perfil reciente es por haberse realizado justo en la desembocadura de la margen derecha del río San Pedro y San Pablo, en tanto que el antiguo perfil del muestreo regional se levantó $4 \mathrm{~km}$ al este de dicha desembocadura,

Tabla 8. Eventos hidrometeorológicos.

\begin{tabular}{lll}
\hline Nombre & Fecha & Tipo \\
\hline Brenda & $18 / 08 / 1973$ & Tormenta \\
Eloisa & $13 / 09 / 1975$ & Tormenta \\
Gilberto & $04 / 09 / 1988$ & Huracán \\
Opal & $02 / 10 / 1995$ & Tormenta \\
Roxanne & $12 / 10 / 1995$ & Huracán \\
Mitch & $02 / 11 / 1998$ & Tormenta \\
Keith & $05 / 10 / 2000$ & Tormenta \\
Isidoro & $19 / 09 / 2002$ & Huracán \\
Wilma & $21 / 10 / 2005$ & Huracán \\
Dean & $21 / 08 / 2007$ & Tormenta \\
Nate & $07 / \mathrm{IX} / 2011$ & Huracán \\
\hline
\end{tabular}

Fuentes: NOAA (2014) y CONAGUA (2014). donde existía aún la carretera que estaba en erosión en el muestreo de 1981; ya Tanner y Stapor Jr. (1971) reportaban erosión para los cordones litorales de Tabasco de esta región. Con la playa Campechito terminan de oeste a este los perfiles de playa constituidos por sedimentos terrígenos.

Los perfiles correspondientes a las playas terrígenas de Tabasco presentan características texturales con menores rangos de variación entre playas antiguas y recientes, observándose sobre todo arenas medias y finas, pero la clasificación de los sedimentos recientes es más pobre comparada con los antiguos (Figura 7), tal vez por influencia antrópica. La simetría de los sedimentos recientes se carga hacia tamaños finos, ello podría deberse a que los ríos cada vez llevan sedimentos más finos por el represamiento, o por otro lado, a que en el sitio de depósito existan mayores niveles de energía, lo cual suele darse cuando hay erosión (Clifton et al., 1979; Cooper et al., 2004; Loureiro et al., 2012). La curtosis es similar entre sedimentos recientes y antiguos, con excepción de la playa oriental de la zona terrígena (Campechito, estación 11) que es extremadamente leptocúrtica lo que parece indicar que hay un aporte muy selectivo de sedimentos o bien que existen condiciones de muy alta energía para dicha estación.

El análisis multivariado de los parámetros estudiados en las muestras de playas terrígenas, las separa en tres grupos caracterizados por el contenido de minerales pesados, el contenido de carbonatos, Qm, FRV, FRM y el contenido de biógenos y Fp.

\subsection{Playas Carbonatadas del sur del Golfo de México}

Desde Playa Norte (Campeche) hasta Champotón (Campeche) los perfiles antiguos y recientes se desarrollaron en costas carbonatadas del sur del Golfo de México. En esta región hay alternancia del litoral rocoso con playas arenosas carbonatadas. El litoral rocoso está compuesto por sedimentos recientes, cementados por carbonato de calcio conocidos como roca de playa o beach rock, por lo que es común encontrarles en las costas tropicales (Kumar et al., 2011). El desnivel de la playa antigua es tres veces mayor que el de la reciente (Figura 5), presentando ésta última un perfil cóncavo, lo cual refleja condiciones erosivas.

En mayo de 1981 (Tabla 1), la estación antigua localizada en Playa Norte, Campeche (Playa 12A, Figura 5) se ubicaba en una posición similar a la del año 1974 (Figura 12). El resto de las líneas de costa, para esta estación, presenta avances y retrocesos en un rango menor que $100 \mathrm{~m}$ lo que hace suponer que este sitio ha sido estable. No obstante, para la estación regional reciente $(12 \mathrm{R})$, que se colectó en mayo de 2007 y se encuentra en el extremo oeste de la Isla del Carmen (cerca de la desembocadura oeste de la Laguna de Términos), se aprecia que la muestra se ubica entre las líneas del 1996 y del 2014, las cuales se traslapan al noroeste de Ciudad del Carmen, Campeche. Respecto a la imagen satelital del 1974 se ve que ha habido una progradación en la Punta de Playa Norte, con un valor máximo para la 
imagen del 27 de enero de 2005 y que probablemente el huracán Wilma del 21 de octubre de 2005 (Tabla 8) produjo un retroceso hacia las condiciones de 2014.

En el caso del perfil de Playa Bahamita (Playa 13, Figura 5), se observa una diferencia notable en la anchura del perfil. Así, en el perfil antiguo no se recibe tanto sedimento como sucede más al oeste donde se levantó el perfil reciente. En este sitio existe una interrupción en la línea costa en lo que Márquez-García (2011) interpreta como una falla, por posible subsidencia, que produce un desplazamiento hacia el sur de la Isla del Carmen, que separa Laguna de Términos del Golfo de México, en la Punta conocida como Briggite Bardot.

En la Playa de Paso Real (Playa 14, Figura 5), localizada más lejos de la boca oeste de Laguna de Términos, se presenta un perfil reciente más angosto asociado con arenas finas y mejor clasificadas que para el perfil antiguo, posiblemente por falta de sedimentos aportados desde esta boca lagunar. La marea está descendiendo en el perfil reciente, mientras que en el perfil antiguo estaba en la cresta de la onda de marea.

En la playa de Isla Aguada (Playa 15, Figura 5), se presentan perfiles parecidos pero en el muestreo reciente el límite superior de las playas no hay palmeras sino pastos, lo que parece sugerir subsidencia del terreno o ascenso de aguas salinas poco propicias para la vegetación superior. En ambos perfiles la marea se encontraba en descenso durante el levantamiento de los perfiles.

Sabancuy (Playa 16, Figura 5) es una playa erosiva sobretodo la más reciente que está próxima al estero de Sabancuy, donde hay una escollera que impide el libre tránsito de sedimentos litorales hacia el oeste. Ambos perfiles se realizaron en mayo con la onda de marea en la cresta, teniendo mayor precipitación media mensual para el perfil antiguo, lo que pudo aportar mayor cantidad de sedimentos a la playa por parte de la boca de Sabancuy. Es posible apreciar que el perfil reciente es cóncavo, característico de condiciones erosivas.

Cuando se hicieron los perfiles de Canchec y de Xochen (Playas 17 y 18, Figura 5), hubo lluvias en mayo con promedios mensuales de $129 \mathrm{~mm}$ durante los perfiles antiguos y de $103 \mathrm{~mm}$ (Tabla 2) para los perfiles recientes. En Canchec el perfil antiguo es más cóncavo que el perfil reciente. Los perfiles de Xochen contrastan bastante, pues el antiguo es corto con dos bermas y el reciente es tres veces más amplio y su convexidad refleja una mayor sedimentación.

El perfil reciente de Champotón (Playa 19, Figura 5) de mayo de 2007 (Tabla 1), está mucho mejor desarrollado que el perfil antiguo. Considerando que para la fecha en que se hizo el muestreo reciente no hubo lluvias ni huracanes, cabe la posibilidad de que el exceso de sedimentación del perfil reciente fuese un remanente del ciclón Dennis que tuvo lugar en julio de 2005 y su perfil cóncavo podría deberse a procesos de erosión.

Para la playa de Champotón (Playa 19, Figura 5) se presenta también una línea de costa que prograda considerablemente (Figura 9) para la línea de 2005. Tanto la muestra antigua, como la reciente, fueron tomadas en el mes de mayo (Tabla 1) de 1981 y 2007 respectivamente. Tal vez el huracán Wilma que se presentó el 21 de octubre de 2005 , con categoría 4 , fue lo suficientemente poderoso para generar una gran afluencia de sedimentos hacia el río Champotón, alejando la línea de costa en los alrededores de la desembocadura del río, sin que el retorno a las condiciones "normales" se hubiera producido de forma inmediata, sino hasta tiempos actuales. Las estaciones de los muestreos regionales (19A y 19R) son próximas entre sí (circa $300 \mathrm{~m}$ ) y ambas se encuentran para los años 1981 y 2007 muy próximas a la línea de costa de 1996.

Los sedimentos carbonatados del sur del Golfo de México presentan mayor dispersión en el tamaño que los sedimentos terrígenos, a pesar de que sobre todo hay arenas medias y arenas finas con la excepción de la estación 14, para la cual se tienen arenas gruesas; estas variaciones en tamaños se pueden deber a las diferencias que hay en las partículas carbonatadas, donde es común encontrar fragmentos recientes de conchas de moluscos cuyo tamaño hace que las partículas resulten más gruesas.

La clasificación más pobre de los sedimentos carbonatados del sur del Golfo de México respecto a los sedimentos terrígenos, tal vez se deba a la variabilidad de tamaños que se presenta por el contenido de biógenos. La estación 14A (Playa Norte) tiene sedimentos mal clasificados, mientras que la $14 \mathrm{R}$ los presenta moderadamente clasificados posiblemente debido a que esta localidad quedó ubicada más cerca de la boca oeste de Laguna de Términos, la cual podría estar influyendo.

Respecto al valor de simetría, se puede decir que a diferencia de las terrígenas, tiene una mayor tendencia a muestras simétricas pero con algunas muestras que son asimétricas hacia tamaños gruesos (valores negativos), lo cual se podría explicar por extremos de la curva con mayor abundancia de partículas gruesas, siendo más comunes las muestras mesocúrticas y leptocúrticas.

Mediante el conteo de biógenos, si se utiliza como límite el $50 \%$, es posible diferenciar el dominio terrígeno del carbonatado. Los porcentajes de biógenos (Figura 8a) en la provincia terrígena se encuentran por debajo de $10 \%$ con excepción de la playa $11 \mathrm{~A}$ (Campechito) que es ligeramente superior a $20 \%$, debido tal vez a una mayor influencia en el pasado de restos biogénicos procedentes de la boca oeste de la Laguna de Términos.

A través del porcentaje de carbonatos (Figura 8b) es aún más contrastante el cambio entre la provincia terrígena y la carbonatada, pues los grupos correspondientes se separan aún más, tal vez porque el efecto de tamaño de partícula de restos biogénicos se minimiza. En este caso la gran mayoría de los sedimentos recientes es más rica en carbonatos que los antiguos, lo que podría deberse a una disminución de terrígenos lo cual propicia un enriquecimiento relativo de carbonatos. 
Carranza-Edwards et al. (1996) encontraron que el segmento litoral de Tabasco, más pobre en carbonatos, está adyacente al segmento litoral de Campeche más rico en carbonatos, porque la corriente de Yucatán detiene su camino hacia el oeste de la boca lagunar occidental de la Laguna de Términos, por encontrarse con la barrera de las descargas fluviales, procedentes de ríos que nacen en tierras elevadas y estribaciones de la Sierra Madre de Chiapas tales como el Grijalva, el San Pedro y San Pablo y el Candelaria, respectivamente.

El enriquecimiento de restos recientes de moluscos (Figura $8 \mathrm{~A}$ ), parece asociarse con una menor influencia de sedimentos terrígenos, en particular, desde la cuenca de los ríos Candelaria y Champotón (Figura 1), lo que podría relacionarse con actividades de manejo y gestión de la zona costera (represamientos, obras costeras, crecimiento demográfico, etc.).

\subsection{Playas Carbonatadas de la Riviera Maya}

Las lluvias mensuales (Tabla 2) promedio son de 101 $\mathrm{mm}$ para Cancún y de $26 \mathrm{~mm}$ para Puerto Morelos. Esta última tiene un perfil antiguo menos cóncavo que el reciente, lo cual se podría deber a procesos erosivos actuales.

Para esta región no fue fácil obtener imágenes, de hecho para las estaciones $21 \mathrm{~A}$ y $21 \mathrm{R}$ sólo se obtuvieron sensores para 1979, 2004 y 2014 (Tabla 7). En la figura 14 se observa que las líneas de costa de 2004 y 2014 coinciden, ya que los sensores L 7 y L8 dan una respuesta similar para estos años, pero el de 1979 (sensor L3) es muy distinto, lo que podría deberse a una menor resolución espacial de imágenes de $60 \mathrm{~m}$, en contraste con los sensores modernos cuya resolución espacial es de $30 \mathrm{~m}$. La posición del punto antiguo 21A, de noviembre de 1982 (Tabla 1), se ubica a una distancia de unos $70 \mathrm{~m}$, mar adentro de la línea de costa actual (Figura 14), lo que parece indicar que para este lapso (1982-2004) en este litoral se presenta erosión. En cambio la estación reciente (21R), de febrero de 2013, prácticamente no se separa de las líneas de 2004 y 2014, lo que sugiere condiciones más estables para los últimos años.

La playa de Cancún (Playa 20, Figura 6) ha sido desde sus inicios una playa antrópica de un gran valor económico por su importancia turística. Esta playa está en continuo proceso de reconstrucción, debido a huracanes como el Gilberto y el Wilma.

En la playa de Puerto Morelos (Playa 21, Figura 6) se aprecia una separación de unos $100 \mathrm{~m}$ entre la línea de costa antigua y la actual (Figura 15), lo que hace pensar que ésta se ha erosionado; en cambio en Playa del Carmen (Playa 22, Figura 6) la ubicación del perfil reciente coincide con la línea de costa actual lo que podría implicar estabilidad hacia los últimos años. No obstante, a unos $1500 \mathrm{~m}$ al suroeste del perfil reciente de Playa del Carmen se da una posible erosión de unos $100 \mathrm{~m}$ a lo largo de ese tramo. La línea de costa de 1976 estaría implicando una severa erosión para años anteriores tal vez relacionada con huracanes o con manejo costero.

A partir del análisis de los mapas que presentan las líneas de costa, antiguas y recientes, se puede concluir que las fuertes diferencias, en la posición de los contornos litorales, pueden encontrar su explicación por el paso de huracanes. El efecto antropogénico sobre la frecuencia e intensidad de los ciclones tropicales aún no está bien entendido (Church et al., 2013) por lo que se debe tomar con reservas. Así por ejemplo, las altas tasas de retroceso de la línea de costa para Punta Disciplina, Campeche (ubicada tan solo a unos $50 \mathrm{~km}$ al este de la estación 11A) se refieren hasta $700 \mathrm{~m}$ desde 1974 hasta 2008 (Torres-Rodríguez et al., 2011; Márquez-García, 2011).

El retroceso de la línea de costa puede responder mejor a fenómenos de subsidencia que a incrementos del nivel del mar, los cuales han sido algunas decenas de mm según Church et al. (2013) por el calentamiento global. El fenómeno de subsidencia se puede dar por una acelerada extracción de fluidos del subsuelo, que de acuerdo con Carranza-Edwards (2010) es factible, particularmente en zonas costeras con una baja pendiente terrestre. No obstante, otra posible causa de este acelerado retroceso de la línea de costa, quizás la más importante, pudo ser el cambio de curso que sufrió el río Usumacinta cuando se conectó con el río Grijalva, dejando como vestigio el actual río San Pedro y San Pablo con una menor capacidad de carga, como lo atestigua la erosión del antiguo delta cuspado del Usumacinta, la cual ha sido reportada por Ortiz-Pérez (1992) entre otros.

En cambio las variaciones que se han dado en la línea de costa de la Riviera Maya se deben sobre todo a variaciones por huracanes o tormentas tropicales y en eso se coincide con Márquez-García et al. (2011), quienes refieren dichos cambios a fenómenos hidrometeorológicos extremos y tal vez a efectos antrópicos relativos al manejo de la zona costera.

En Playa del Carmen (Playa 22, Figura 6), se contaba originalmente con un perfil de playa muy bien desarrollado, donde existía una berma que terminaba en dunas con vegetación en el límite de la supra playa, mientras que para agosto de 2005 (Tabla 1) ya está limitado por bardas de concreto debido al gran desarrollo demográfico. Cuando se levantó el perfil reciente, la onda de marea se encontraba en valle (Tabla 2, Figura 6) y a pesar de ello se observa una falta de desarrollo vertical del perfil (2.5 veces menor que el antiguo), lo cual podría deberse a condiciones erosivas o a una disminución de sedimentos litorales procedentes del sur por un inadecuado manejo costero.

En el caso de Playa Akumal (Playa 23, Figura 6) los perfiles son cortos (10 m el antiguo y $25 \mathrm{~m}$ el reciente) y con pendientes similares. Se trata de una playa protegida por encontrarse en una semi caleta. En el año 1988, la playa se vio colmada de sedimentos como efecto del huracán Gilberto y su exceso de sedimentación le quitó atractivo por algún tiempo.

Las muestras de la Riviera Maya a pesar de ser sólo 
cuatro muestras antiguas y cuatro recientes de sedimentos de playas, cubren rangos de tamaños similares a las correspondientes carbonatadas del Golfo de México, es decir su Mz $\phi$ varía también entre $0.50 \phi$ y $2.50 \phi$, tratándose de arenas que cambian desde gruesas hasta finas. Respecto al valor de la clasificación presentan menos dispersión que las carbonatadas del Golfo de México y parece ser que de norte a sur de la Riviera Maya se observa una tendencia a una clasificación más pobre, que tal vez se asocie con mayores niveles de energía hacia Cancún (estación 20) que hacia Akumal (estación 23), siendo esta última una playa semiprotegida.

De la simetría cabe decir que las muestras recientes presentan valores de asimétricos hacia finos y muy finos, en tanto que las antiguas tienden a valores más asimétricos hacia tamaños gruesos, a pesar de ser una población pequeña de datos. Tal vez haya más aportes de descargas de lodos antrópicos finos dado el crecimiento demográfico de la región.

Los valores de curstosis (Figura 7) tienden a ser similares a los observados en las otras regiones, pero para el caso de Akumal (23A) la muestra era muy leptocúrtica debido a que aún no se presentaban procesos de mezclas como los que se dieron cuando ocurrieron los huracanes Gilberto y Wilma; es decir, se tenían condiciones de calma y tal vez menos aportes antrópicos.

El análisis multivariado de los parámetros estudiados en las muestras de playas carbonatadas con información de carbonatos, parámetros texturales y organismos, las agrupa en cuatro grupos caracterizados por: 1) tamaño de partícula, 2) bajo contenido de carbonatos y biógenos, 3) alto contenido de biógenos y 4) simetría, curtosis y foraminíferos.

En general se observa que cuando se comparan los perfiles recientes de playas con perfiles antiguos en periodos comprendidos entre 26 y 32 años, las longitudes de las playas varían mucho independientemente del estado de la marea y se puede decir que para la mayoría de las playas del sur del Golfo de México los perfiles recientes tienden a ser más largos que los antiguos y también con frecuencia presentan perfiles cóncavos indicadores de erosión. Cabe señalar que en la parte superior de las playas cada vez son menos frecuentes las palmeras en los perfiles playeros modernos.

Los sedimentos carbonatados del sur del Golfo de México y de la Riviera Maya presentan mayores rangos de variación, lo cual se puede deber a las variaciones en contenidos de restos marinos recientes de biógenos de diversa naturaleza y tamaño. También cabe señalar que para la Riviera Maya los sedimentos recientes tienen más valores hacia tamaños finos que los más antiguos, lo que parece indicar alguna influencia de descargas antrópicas, como serían las descargas de aguas urbanas de desechos.

Para el caso de los sedimentos carbonatados del sur del Golfo de México y de la Riviera Maya, los pellets arrojaron información muy interesante, pues para todos los casos sus concentraciones fueron menores para los sedimentos recientes que para los antiguos. La fuerte disminución en la concentración de pellets (Tabla 6, Figura 9b) podría asociarse con el crecimiento demográfico y con la propia mancha urbana correspondiente, por una disminución de organismos litorales, y de aves marinas y terrestres, pues a un mayor crecimiento poblacional sin gestión costera adecuada correspondería una disminución de vegetación $\mathrm{y}$ un aumento en la contaminación de playas, ambas vulnerando a las poblaciones de organismos relacionados con el ambiente de playa.

Los factores antrópicos y los fenómenos naturales extremos (huracanes, tormentas tropicales, fuertes vientos del norte, etc.) juegan un papel importante en las playas; por ejemplo, en las Figuras 12 y 13 se aprecian en los alrededores de Playa Norte y Champotón, Campeche, considerables avances y retrocesos de la línea de costa respectivamente, posiblemente relacionados con fenómenos meteorológicos y antrópicos.

\section{Conclusiones}

La mayoría de los perfiles de playa recientes resultaron ser más largos que los antiguos, lo que parece deberse a que los perfiles recientes se hicieron en temporadas con mayor precipitación. Sin embargo, la forma de los perfiles de playas recientes se presenta con mayor concavidad que los antiguos, lo que sugiere que éstos están sujetos a una mayor erosión. El estado de la marea no parece influir en la longitud de los perfiles.

A partir de la comparación de parámetros texturales se destaca particularmente que de las 23 muestras recientes, 20 están más pobremente clasificadas que las antiguas, debido posiblemente a fenómenos de mezclas por actividad antrópica.

La presencia de biógenos marinos recientes y el contenido de carbonatos en las arenas de playa marcan una diferencia contrastante entre sedimentos terrígenos y carbonatados, cuya delimitación se encuentra entre la playas de Campechito (Camp.) y de Playa Norte (Camp.). Al oeste de Campechito son sedimentos terrígenos y al este de Playa Norte y en la Riviera Maya se tiene un dominio carbonatado.

La elevación del nivel del mar reportado por el IPCC para los últimos 30 años (Church et al., 2013) ha sido de 5 $\mathrm{cm}$ por lo que en los mapas de variabilidad de la línea de costa se dan casos de acreción y erosión en forma indistinta, pareciendo estar controladas por el paso de huracanes, que tienen efectos tanto de erosión como de acreción. En esta investigación regional se observa que a toda erosión corresponde una sedimentación y si estos procesos tienen causas antrópicas, la vulnerabilidad ambiental se incrementa.

Para la variación temporal de líneas de costa en el Puerto de Dos Bocas, se encontró que la localidad antigua se ubica tierra adentro debido a la construcción de una gran escollera, 
mientras que la localidad reciente refleja erosión.

Las playas al este de la desembocadura del río Grijalva sufren acreción, mientras que al oeste se han erosionado, debido posiblemente a un proceso antrópico ligado con la retención de sedimentos en la escollera oriental.

El análisis de componentes principales incluyendo todos los parámetros estudiados, clasifica a las playas en función de: 1) su contenido de carbonatos, 2) su tamaño de grano y 3) la pendiente de la playa.

Los minerales pesados sugieren una mayor energía en el ambiente, mientras que los pellets siempre se encontraron en menores concentraciones en los sedimentos recientes, lo que sugiere una menor cantidad de organismos litorales $\mathrm{y}$ de aves que son productores de pellets fecales, tal vez debido al impacto antrópico de pérdida de vegetación por crecimiento de las manchas urbanas.

La movilidad de sedimentos y variaciones de líneas de costa están controladas por factores tanto naturales como antrópicos. Entre los principales factores naturales se puede mencionar: 1) las precipitaciones relacionadas con tormentas o huracanes y 2) disminución del aporte de sedimentos al litoral del sur del Golfo de México por la desviación del río Usumacinta hacia el cauce del río Grijalva, lo cual pudo suceder por un taponamiento natural o por derrumbes. Los principales factores antrópicos que intervienen en cambios de la línea de costa se consideran: 1) obstáculos al transporte litoral de los sedimentos por escolleras, tuberías submarinas no sepultadas, 2) formación de marinas o sitios de excavación de materiales en zonas litorales y 3 ) aparentemente en menor grado, el ascenso del nivel del mar por calentamiento global.

\section{Agradecimientos}

Se agradece a las autoridades del Instituto de Ciencias del Mar y Limnología de la Universidad Nacional Autónoma de México y las autoridades del Departamento de Hidrobiología de la UAM Iztapalapa de la Universidad Autónoma Metropolitana por el apoyo otorgado para la realización de este artículo.

Se agradece por su apoyo al M. en C. Eduardo Morales de la Garza y al laboratorista Ricardo Martínez Domínguez en los análisis granulométricos y a la QFB. Susana Santiago Pérez en los análisis químicos. Asimismo a los numerosos académicos (investigadores, técnicos y alumnos) que colaboraron en los diversos trabajos de campo tanto en los muestreos antiguos como en los recientes.

\section{Referencias}

Alesheikh, A.A., Ghorbanali, A., Nouri, N., 2007, Coastline change detection using remote sensing: International Journal of Environmental Science and Technology, 4 (1), 61-66.

Arkema, K.K., Guannel, G., Verutes, G., Wood, S. A., Guerry, A., Ruckelshaus, M., Silver, J. M., 2013, Coastal habitats shield people and property from sea-level rise and storms: Nature Climate Change, 3, 913-918.

Basu, A., 1976, Petrology of Holocene fluvial sand derived from plutonic source rocks: implication to paleoclimatic interpretation: Journal of Sedimentary Petrology, 46, 694-709.

Carranza-Edwards, A., Caso Chávez, M., 1994, Zonificación del perfil de playa: Geo-UNAM, 2 (2), 26-32.

Carranza-Edwards, A., Rosales-Hoz, L., Santiago-Pérez, S., 1996, A reconnaissance study of carbonates in Mexican beach sands: Sedimentary Geology, 101, 261-268.

Carranza-Edwards, A., 2001, Grain size and sorting in modern beach sands: Journal of Coastal Research, 17, 38-52.

Carranza-Edwards, A., 2010, Causas y consecuencias de la erosión de playas, en Yáñez-Arancibia, A., (ed.), Texas Sea Grant Program, Instituto Nacional de Ecología: Impactos del Cambio Climático sobre la Zona Costera, Instituto de Ecología A. C., Xalapa, Ver., $37-50$.

Castellanos-Trujillo, L., 1992, Concentración teórica de ilmenita contenida en playas de Tabasco y Campeche: Anales Instituto Ciencias del Mar y Limnología, Universidad Nacional Autónoma de México, 19 (2), 131-135

Church, J.A., Clark, P.U., Cazenave, A., Gregory, J.M., Jevrejeva, S., Levermann, M.A., Merrifield, M.A., Milne, M.A., Nerem, R.S., Nunn, P.D., Payne, A.J., Pfeffer, W.T., Stammer, D., Unnikrishnan, A.S., 2013, Sea Level Change, Climate Change 2013, The Physical Science Basis. Contribution of Working Group I to the Fifth Assessment Report of the Intergovernmental Panel on Climate Change, en Stocker, T.F., Qin, D., Plattner, G.K., Tignor, M., Allen, S.K., Boschung, J., Nauels, A., Xia, Y., Bex, V., Midgley P.M. (eds.): Cambridge University Press, Cambridge, United Kingdom and New York, NY, USA., 1137-1216.

Clifton, H.E., Hunter, R.E., Phillips, R.L., 1971, Depositional structures and processes in non-barred high-energy nearshore: Journal of Sedimentary Petrology, 41, 651-670.

Comisión Nacional del Agua (CONAGUA), 2014, Precipitación Mensual en México, disponible en < http://smn.cna.gob.mx/emas/ >, consultado en $12 /$ febrero/2014.

Cooper, J.A.G., Jackson, D.W.T., Navas, F., McKenna, J., Malvarez, G., 2004, Identifying storm impacts on an embayed, high-energy coastline: Examples from western Ireland: Marine Geology, 210, 261-280.

Duncan, M.F., Fenster, M.S., Argow, B.A., Buynevich, I.V., 2008, Coastal Impacts Due to Sea-Level Rise: Annual Review of Earth and Planetary Sciences, 36, 601-647.

Ergin, M., Keskin, Ş., Doğan, A. U., Kadioğlu, Y. K., Karakaş, Z., 2007, Grain size and heavy mineral distribution as related to hinterland and environmental conditions for modern beach sediments from the Gulfs of Antalya and Finike, eastern Mediterranean: Marine Geology, 240, 185-196.

Fanos, A.M., 1995, The Impact of Human Activities on the Erosion and Accretion of the Nile Delta Coast: Journal of Coastal Research, $11,821-833$.

Feagin, R.A., Sherman, D.J., Grant, W.E., 2005, Coastal erosion, global sea-level rise, and the loss of sand dune plant habitats: Frontiers in Ecology and the Environment, 3 (7), 358-364.

Fernández-Eguiarte, A., Gallegos-García, A., Zavala-Hidalgo, J., 1992a, Oceanografía Física 1 (Masas de Agua y Mareas de los Mares Mexicanos), Hoja IV.9.1, Verano, escala 1:4000000, en Atlas Nacional de México, Tomo II, IV. Naturaleza, 9. Oceanografía Física: México, D.F., Universidad Nacional Autónoma de México, Instituto de Geografía, 1 mapa.

Fernández-Eguiarte, A., Gallegos-García, A., Zavala-Hidalgo, J., 1992b, Oceanografía Física 1 (Masas de Agua y Mareas de los Mares Mexicanos), Hoja IV.9.2, Invierno, escala 1:4000000 en Atlas Nacional de México, Tomo II, IV. Naturaleza, 9. Oceanografía Física: México, D.F., Universidad Nacional Autónoma de México, Instituto de Geografía, 1 mapa.

Folk, R.L., 1980, Petrology of Sedimentary rocks: Austin, Texas, Hemphill Publishing Co.,182 p. 
Franzinelli, E., Potter, P.E., 1983, Petrology, chemistry and texture of modern river sands, Amazon River System: Journal of Geology, 91, 23-29.

Hair, J.F., Anderson, R.E., Tatham, R.L., Black, W.C., 1998, Multivariate Data Analysis, Prentice Hall, $730 \mathrm{p}$.

Hernández Santana, J.R., Ortiz Pérez, M.A., Méndez Linares, A.P., Campillo, L.G., 2008, Morfodinámica de la línea de costa del estado de Tabasco: tendencias desde la segunda mitad del siglo XX hasta el presente, Investigaciones Geográficas: Boletín del Instituto de Geografía, Universidad Nacional Autónoma de México, 65, 7-21.

Hesse, P.R., 1971, A textbook of soil chemical analysis, London, John Murray, $520 \mathrm{p}$.

Instituto de Geofísica, 1991, Tablas de predicción de mareas. Puertos del Golfo de México y Mar Caribe. Datos Geofísicos Serie A Oceanografía, $191 \mathrm{p}$.

King C.A.M., 1972, Beaches and Coasts: London, UK., Edward Arnold, $570 \mathrm{p}$.

Komar, P.D., Wang, C., 1984, Processes of selective grain transport and the formation of placers on beaches: Journal of Geology, 92, 637-655.

Kumar, S.K., Chandrasekar, N., Seralathan, P., Godson, P.S., 2011, Depositional environment and faunal assemblages of the reefassociated beach rock at Rameswaram and Keelakkarai Group of Islands, Gulf of Mannar, India: Frontiers of Earth Sciences, 5, 61-69.

Loska, K., Wiechula, D., 2003, Application of principal component analysis for the estimation of source of heavy metal contamination in surface sediments from the Rybnik Reservoir: Chemosphere, 51, 723-733.

Loureiro, C., Ferreira, Ó., Cooper, J. A. G., 2012, Extreme erosion on high-energy embayed beaches: Influence of megarips and storm grouping: Geomorphology, 139-140, 155-171.

Marín-Guzmán A.P. y Carranza-Edwards, A., 2011, Inferencia de transporte litoral dominante del Golfo de México, en Gío-Argáez R. y Rosales-Hoz, M. T. L. (eds.), Instituto de Ciencias del Mar y Limnología, Universidad Nacional Autónoma de México, México, D.F., Interacciones en el Planeta Tierra: Editorial Universidad Nacional Autónoma de México, 39-46.

Márquez-García, A.Z., 2010, Procesos de erosión y depositación en el litoral sur del Golfo de México: México, Posgrado en Ciencias del Mar y Limnología, Universidad Nacional Autónoma de México, Tesis Doctoral, $187 \mathrm{p}$.

Márquez-García, A.Z., Márquez-García, Bolongaro-Crevenna, A., Torres-Rodríguez, V., 2011, Cambio en la línea de costa en la Riviera Maya debido a fenómenos hidrometeorológicos extremos: ¿Consecuencia del cambio global climático?, en Botello, A.V., Villanueva-Fragoso, S., Gutiérrez, J., Rojas-Galaviz J.L. (eds.), Vulnerabilidad de las Zonas Costeras Mexicanas ante el Cambio Climático (segunda edición): Campeche, Universidad Autónoma de Campeche, 433-446.

Merino-Ibarra, M., 1986, Aspectos de la circulación costera superficial del caribe mexicano con base en observaciones utilizando tarjetas de deriva: Anales del Instituto de Ciencias del Mar y Limnología, Universidad Nacional Autónoma de México, 13 (2), 31-46.

Mico, C., Recatala, L., Peris, M., Sánchez, J., 2006, Assessing heavy metal sources in agricultural soils of an European Mediterranean Area by multivariate analysis: Chemosphere, $65,863-872$.
National Oceanographic and Atmospheric Administration (NOAA), 2014, Tropical Cyclone History: Data from 1949 in the Pacific, from 1851 in the Atlantic, National Hurricane Center, disponible en $<\mathrm{http}: / /$ www.nhc.noaa.gov/climo/images/1851_2013_tc.jpg>

Ortega-Gutiérrez, F., Mitre-Salazar, L.M., Roldán-Quintana, J., ArandaGómez, J.J, Morán- Zenteno, D., Alaniz-Álvarez, S.A., NietoSamaniego, A.F., 1992, Texto Explicativo de la Quinta Edición de la Carta Geológica de la República Mexicana, scale 1:2000000, México, D.F.: Universidad Nacional Autónoma de México, Instituto de Geología y Consejo de Recursos Minerales, 74 p.

Ortíz, M.A., 1992. Retroceso reciente de la línea de costa del frente deltaico del río San Pedro, Campeche-Tabasco: Boletín Instituto de Geografía, 25, 7-23.

Peizhen, Z., Molnar, P., Downs, W.R., 2001, Increased sedimentation rates and grain sizes 2-4 MY ago due to the influence of climate change on erosion rates: Nature, 410, 891-897.

Potter, P.E., 1978, Petrology and chemistry of modern big river sands: Journal of Geology, 86, 423-449.

Roy, P.S., 1999, Heavy mineral beach placers in Southeastern Australia: Their nature and genesis: Economic Geology, 94, 567-588.

Tamayo, J.L., 1990, Geografía Moderna de México: Ciudad de México, Trillas, $400 \mathrm{pp}$.

Tanner, W., Stapor, Jr, F.W., 1971, Tabasco beach-ridge plain: an eroding coast: Transactions - Gulf Coast Association of Geological Societies, 21, 231-232.

Torres-Rodríguez, V., Márquez-García, A.Z., Bolongaro-Crevenna, A., Chavarría-Hernández, J., Exposito-Díaz, G., Márquez-García, E., 2011, Tasa de erosión y vulnerabilidad costera en el estado de Campeche debido a efectos del cambio climático, en Botello, A.V., Villanueva-Fragoso, S., Gutiérrez, J., Rojas-Galaviz J.L. (eds.), Vulnerabilidad de las Zonas Costeras Mexicanas ante el Cambio Climático (segunda edición): Universidad Autónoma MetropolitanaIztapalapa, UNAM-ICMyL, Universidad Autónoma de Campeche, 413-432.

West, R.C., Psuty, P., Thom, B., 1976, Las Tierras Bajas de Tabasco en el sureste de México: México, Gobierno del Estado de Tabasco, 409 p.

Yáñez-Arancibia, A., Lara-Dominguez, A.L, Rojas-Galaviz, J.L., Villalobos-Zapata, G. J., Zárate, D.J., Sánchez-Gil, P., 1999, Integrated coastal zone management plan for Terminos Lagoon, Campeche, México, en Kump, H., Sherman, K. (eds.), The Gulf of Mexico Large Marine Ecosystem, Malden, Mass., Blackwell Science Inc., 565-92.

Yuill, B., Lavoie, D., Reed, D.J., 2009, Understanding Subsidence Processes in Coastal Louisiana: Journal of Coastal Research, Special Issue $54,23-36$.

Manuscrito recibido: Junio 7, 2014.

Manuscrito corregido recibido: Octubre 13, 2014.

Manuscrito aceptado: Octubre 17, 2014. 